\title{
Do Currency Fundamentals Matter for Currency Speculators?
}

\author{
Masahiro Nozaki
}




\title{
IMF Working Paper
}

Western Hemisphere Department

Do Currency Fundamentals Matter for Currency Speculators?

Prepared by Masahiro Nozaki ${ }^{1}$

Authorized for distribution by Andreas Bauer

February 2010

\begin{abstract}
This Working Paper should not be reported as representing the views of the IMF. The views expressed in this Working Paper are those of the author(s) and do not necessarily represent those of the IMF or IMF policy. Working Papers describe research in progress by the author(s) and are published to elicit comments and to further debate.
\end{abstract}

The answer seems affirmative. We compare currency carry trades with an investment strategy based on currency fundamentals: taking a long (short) position in undervalued (overvalued) currencies. Carry trades have high risk-adjusted returns, but are subject to "crash risk." In contrast, the fundamental strategy has lower risk-adjusted returns, but is less prone to crash risk, because the realization of crash risk coincides with corrections towards fundamentals. In particular, the fundamental strategy outperformed carry trades during the recent global financial crisis. Building on these results, we present early warning indicators for potential turbulence in the currency market.

JEL Classification Numbers: G11, G15, F31.

Keywords: currency speculation, carry trades, currency fundamentals.

Author's E-Mail Address:mnozaki@imf.org

\footnotetext{
${ }^{1}$ The author would like to thank Gian Maria Milesi-Ferretti and Jungin Lee for earlier comments and support, and is also grateful to Andreas Bauer, Martin Cerisola, Ruo Chen, Rodolfo Luzio, Andre Meier, Ken Miyajima, Mauro Roca, Kevin Ross, Rodrigo Valdes, Hiromi Yamaoka, and seminar participants at the IMF, for their comments and suggestions.
} 
I. Introduction

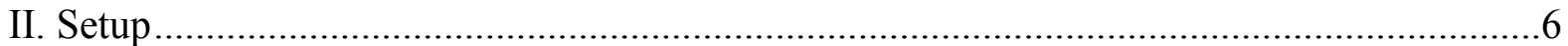

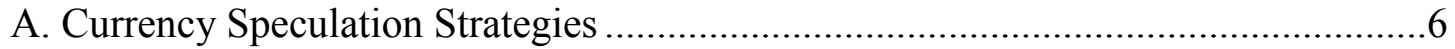

B. Currency Fundamental Values ...........................................................................

III. Results

A. The Sharpe Ratio and Skewness ............................................................. 10

B. The Source of Negative Skewness and Improvements under the Fundamental

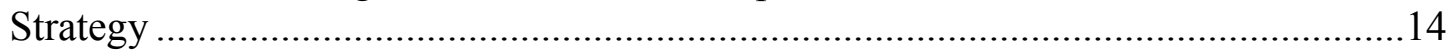

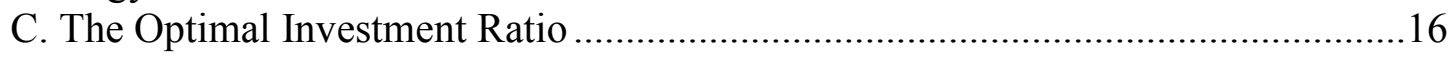

D. Currency Speculation and the Global Financial Crisis ....................................... 17

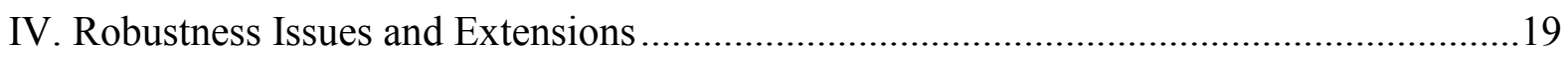

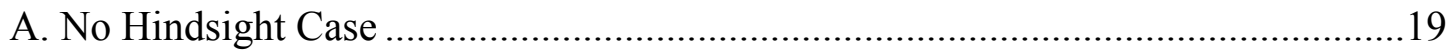

B. Gains from Incorporating Determinants of Currency Fundamentals .....................23

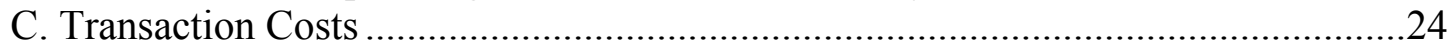

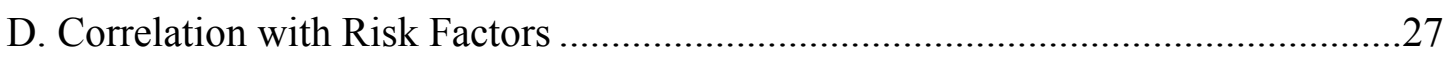

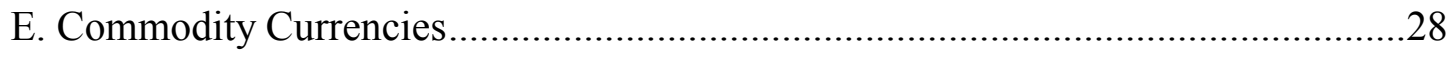

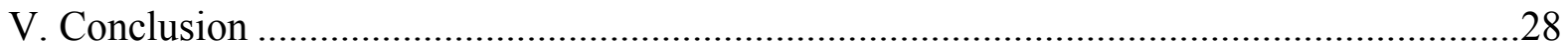

Tables

1. Tests for Unit Root and Cointegration.................................................... 7

2. Estimates of the Cointegration Vector.............................................................. 8

3. Performance of Currency Speculation Strategies.................................................. 11

4. Performance of Currency Speculation Strategies: Subsamples.............................. 14

5A. Sources of Negative Skewness for the Carry Trade Strategy.................................. 15

5B. Realized Returns of the Equally Weighted Portfolio during Dismal Months of CT.. 15

6. Optimal Investment and Utility Levels............................................................... 17

7. Performance of Currency Speculation Strategies during the Recent Global

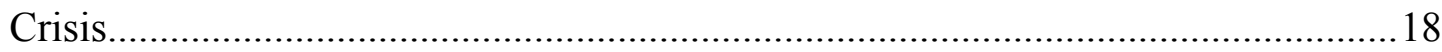

8A. Performance of Currency Speculation Strategies: No Hindsight Case..................... 22

8B. Sources of Negative Skewness for the Carry Trade Strategy (No Hindsight Case)... 22

8C. Optimal Investment and Utility Levels............................................................ 22

9. Performance of Currency Speculation Strategies: PPP and HP Filter Cases............. 24

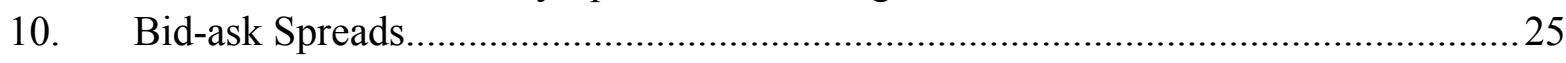

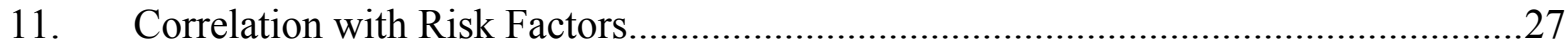

12. Performance of Currency Speculation Strategies: Commodity Currencies.............. 28

Figures

1. REER and Bilateral Exchange Rate vis-à-vis U.S. Dollar, 1985-2008................... 9 
2. Sharpe Ratio and Skewness for Currency Speculation Strategies.......................... 12

3. Sharpe Ratio and Skewness: Equally Weighted Portfolio..................................... 13

4. Gap Index, Divergence Index, and VIX, 2000-2008 ............................................ 19

5. Panel Regression Coefficients with Moving Sample Periods...................................2 20

6. Sharpe Ratio and Skewness for Currency Speculation Strategies (No Hindsight

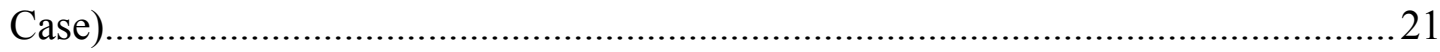

7. Sharpe Ratio and Skewness for Currency Speculation Strategies (with Transaction

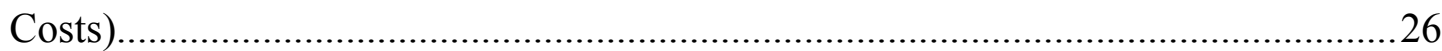

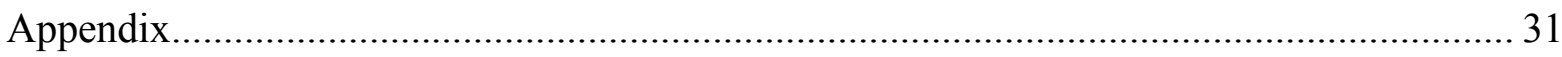

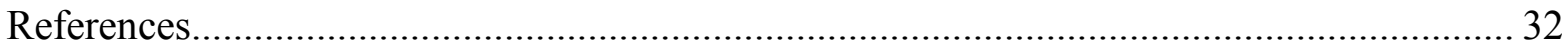




\section{INTRODUCTION}

Currency carry trades have attracted investors because of their high risk-adjusted returns. Carry traders take a short position in a currency with a low interest rate and a long position in a currency with a high interest rate. For example, before the onset of the jitters in global financial markets in the summer of 2007, a typical carry trade strategy comprised a short position in the Japanese yen and a long position in the New Zealand dollar. As documented by many researchers, carry traders take advantage of the "forward premium puzzle" - the failure of the uncovered interest rate parity to hold over a short time horizon - and benefit from a high Sharpe ratio (Burnside et al (2006) and Brunnermeier et al (2008)). A possible explanation for the high Sharpe ratio of carry trades is that it represents the price of crash risk, i.e., sudden adjustments in the exchange rate. In the fall of 1998, for example, the Japanese yen appreciated against the U.S. dollar by 15 percent in two weeks, causing a large loss for carry traders who took a short position in the yen.

In this paper, we study returns to currency speculation by comparing typical carry trades with strategies guided by the fundamental value of currencies. We define a "fundamental" strategy under which investors take a long (short) position in a currency that is undervalued (overvalued) relative to its fundamental value. The fundamental value is estimated from a cross-country panel regression for the real effective exchange rate (REER), which takes into account terms of trade developments and the Balassa-Samuelson effect. Although such a strategy appears sensible, it may not be profitable because of the slow speed of adjustment of the exchange rate toward its fundamental value. As observed by Rogoff (1996), the half life of a deviation from the purchasing power parity (PPP) can be as long as three to five years.

In evaluating the performance of currency speculation strategies, we find that the fundamental values of currencies do matter. We compare the historical rates of return of different currency speculation strategies for nine advanced country currencies, assuming that investors adjust their positions on a monthly basis. As observed by other studies, the carry trade strategy results in a high Sharpe ratio, but its returns are negatively skewed and are subject to crash risk with occasional events of dismal returns. In contrast, the fundamental strategy leads to a much lower Sharpe ratio, but its returns are positively skewed and hence somewhat crash-risk proof. Moreover, in periods of large swings in the exchange rate, the fundamental strategy performs better than the carry trade strategy. A "hybrid" of the two strategies - to follow the carry trade strategy if exchange rate overvaluation or undervaluation is within a threshold ( 5 or 10 percent), and to switch to the fundamental strategy otherwise - has a relatively high Sharpe ratio, while providing some insurance against crash risk. We find that a utility-maximizing investor would opt for the hybrid strategy over the carry trade strategy or the fundamental strategy. All in all, our results suggest that the crash risk inherent in carry trades materializes as a result of exchange rate adjustments toward their fundamental value.

In fact, we find that the fundamental strategy strongly outperformed the carry trade strategy during the recent global financial crisis. This suggests that exchange rates experienced corrections toward their estimated fundamental values during the crisis - the contingency insured by the fundamental and hybrid strategies. Moreover, in the period leading up to the 
global crisis, undervalued currencies had had lower interest rates, and vice versa, possibly causing a "bubble" in the foreign exchange markets as carry trades aggravated exchange rate overvaluation or undervaluation. Such a boom-bust cycle could be the mechanism underlying Brunnermeier et al (2008)'s observation that rising risk aversion, as measured by the VIX index, coincides with increased losses for carry traders. Based on these observations, we present indices that could serve as an early warning signal to spot risk of a sudden and sharp swing in the exchange rates.

Our result is counterintuitive to the view of slow adjustment of exchange rates toward their fundamental value. With slow adjustment, exchange rate overvaluation or undervaluation should not matter for investors who change their positions frequently on a monthly basis. However, we find that the fundamental value of a currency carries valuable information for currency speculators, because it signals a possibility of a large and quick adjustment of the exchange rate (i.e., crash risk). This is consistent with the idea of nonlinear adjustments in the exchange rate: the larger the divergence from the equilibrium exchange rate is, the faster the exchange rate adjusts (Taylor, Peel, and Sarno (2001)). If the high risk-adjusted returns of carry trades are compensation for crash risk, and crash risk is related to the nonlinear adjustment of the exchange rate, the nonlinearity can be a key to explain the forward premium puzzle.

The main findings of this paper are shared with recent research by Jordà and Taylor (2009). They find that fundamental-based strategies for currency speculation, especially those that incorporate the nonlinear adjustment of the exchange rate, outperform carry trades since they are crash-risk proof. In their paper, however, the fundamental-based strategies are guided by the relative PPP, and do not take into account the determinants of the equilibrium REER such as terms of trade. In contrast, we find that the fundamental-based strategies with these determinants generally outperform those guided only by the relative PPP, in terms of the Sharpe ratio and the skewness of returns.

Lastly, this paper is related to studies on the predictive power of the so-called CGER exchange rate assessments developed by the IMF. The CGER methodology comprises three approaches to estimate equilibrium real effective exchange rates and gauge overvaluation and undervaluation of currencies, including a panel regression of the real effective exchange rate on fundamentals, like the one used in this paper. Abiad, Kannan, and Lee (2009) find that the estimated undervaluation or overvaluation from the CGER exercise has some predictive power for future movements in the exchange rate in the long run. In contrast, this paper analyzes financial returns from currency speculation, and the predictive horizon is in a sense much shorter than theirs, because we measure returns on a monthly basis.

This paper is organized as follows. Section 2 describes our methodology to compute returns to currency speculation strategies, and Section 3 analyzes the performance of these strategies. Section 4 discusses robustness issues and extensions, and Section 5 concludes. 


\section{SETUP}

\section{A. Currency Speculation Strategies}

We calculate and compare monthly returns achieved by various currency speculation strategies. Let $S_{i t}$ and $F_{i t}$ denote the spot and forward exchange rates of foreign currency $i$ (defined as foreign currency units per U.S. dollar), respectively. From the covered interest parity (CIP) we have $\frac{1+R_{i t}^{*}}{1+R_{t}}=\frac{F_{i t}}{S_{i t}}$, where $R_{i t}^{*}$ and $R_{t}$ are the foreign and the U.S. interest rates, respectively.

If an investor takes an uncovered position of $X_{i t}$ dollars in foreign currency $i$ (a positive value of $X_{i t}$ means a long position in the foreign currency), the ex post payoff $Z_{i t}$ is defined as

$$
Z_{i, t+1}=X_{i t}\left[\left(1+R_{t}^{*}\right) \frac{S_{i t}}{S_{i, t+1}}-\left(1+R_{t}\right)\right]=\left(1+R_{t}\right) X_{i t}\left[\frac{F_{i t}}{S_{i, t+1}}-1\right] .
$$

We normalize $X_{i t}$ to one U.S. dollar, so that an investor chooses between $X_{i t}=-1$ (a short position) and $X_{i t}=+1$ (a long position). The resulting $Z_{i t}$ measures excess returns.

We calculate $Z_{i t}$ from February 1985 to December 2008 for nine advanced-economy currencies: the Australian dollar, the Canadian dollar, the Danish krone, the Japanese yen, the New Zealand dollar, the Norwegian krone, the Swedish krona, the Swiss franc, and the pound sterling. The euro, which was only introduced in 1999, is not included because of insufficient observations. Since we calculate $Z_{i t}$ on a monthly basis, $F_{i t}$ is the forward exchange rate one month ahead, and $X_{i t}$ is adjusted each month. The exchange rate data are obtained from the Datastream database (see Appendix for details). For $R_{t}$, we use the onemonth euro dollar interest rate published by the U.S. Federal Reserve.

We next define currency speculation strategies. First, the carry trade strategy is characterized as taking a long (short) position in a foreign currency if the interest rate of the foreign currency is higher (lower) than that of the U.S. dollar. Using the CIP, this strategy is defined as

$$
X_{i t}^{C T}=\left\{\begin{array}{ll}
+1 & \text { if } F_{i t} / S_{i t} \geq 1 \\
-1 & \text { if } F_{i t} / S_{i t}<1
\end{array} \text { for currency } i=1, \cdots, 9 .\right.
$$

Second, the fundamental strategy is a strategy under which an investor takes a long (short) position in a foreign currency if it is undervalued (overvalued) in comparison to its "fundamental" value. Let $W_{i t}$ denote the real effective exchange rate of foreign currency $i$ (in $\log$ ), and $W_{i t}^{*}$ be its estimated fundamental value. Then, the fundamental strategy is defined as 


$$
X_{i t}^{F M}=\left\{\begin{array}{ll}
+1 & \text { if } W_{i t} \leq W_{i t}^{*} \\
-1 & \text { if } W_{i t}>W_{i t}^{*}
\end{array} .\right.
$$

The empirical methodology to estimate $W_{i t}^{*}$ is presented in the next subsection.

Third, the hybrid strategy is a "hybrid" between the carry trade and the fundamental strategy, defined as follows:

$$
X_{i t}^{H B}=\left\{\begin{array}{cc}
+1 & \text { if } W_{i t}<W_{i t}^{*}-\alpha \\
-1 & \text { if } W_{i t}>W_{i t}^{*}+\alpha \\
X_{i t}^{C T} & \text { otherwise. }
\end{array}\right.
$$

Thus, an investor switch from the carry trade strategy to the fundamental strategy if the overvaluation or undervaluation of the foreign currency exceeds $\alpha \times 100$ percent. We will consider two cases of $\alpha=0.05$ and $\alpha=0.10$. The idea of the hybrid strategy is closely related to nonlinear adjustments of the exchange rate toward its fundamental value: the larger the divergence from the equilibrium exchange rate is, the faster the exchange rate adjusts. In other words, if the divergence exceeds a threshold, the exchange rate may adjust so rapidly that carry traders incur a substantial loss. Switching to the fundamental strategy may avoid such losses.

\section{B. CURRency Fundamental VAlues}

The estimation of the fundamental value of a foreign currency, $W_{i t}^{*}$, is based on a panel estimate of the equilibrium real effective exchange rate. The panel dataset comprises 21 advanced countries and is on an annual basis for 1981-2008. The 21 countries (which include the issuers of currencies of our interest) are: Australia, Austria, Belgium, Canada, Denmark, Finland, France, Germany, Greece, Ireland, Italy, Japan,

Netherlands, New Zealand, Norway, Portugal, Spain, Sweden, Switzerland, United Kingdom, and United States.

Following Lane and Milesi-Ferretti (2004) and Lee et al (2008), the real effective exchange rate (REER) is regressed onto three possible determinants of its equilibrium value: the commodity-based terms of trade to capture the well-documented positive

\begin{tabular}{|c|c|c|}
\hline & Statistics & P-value \\
\hline \multicolumn{3}{|l|}{ I. Panel unit root tests } \\
\hline Real effective exchange rate & 5.75 & 0.00 \\
\hline Relative GDP per capita & 11.26 & 0.00 \\
\hline Commodity terms of trade & 4.26 & 0.00 \\
\hline Net foreign assets (in percent of GDP) & 9.24 & 0.00 \\
\hline Net foreign assets (in percent of trade) & 10.07 & 0.00 \\
\hline \multicolumn{3}{|c|}{$\begin{array}{l}\text { II. Panel cointegration test for real effective exchange rate, } \\
\text { relative GDP per capita, and commodity terms of trade }\end{array}$} \\
\hline \multicolumn{3}{|c|}{ Alternative hypothesis: common autocovariance coefficients } \\
\hline v-statistic & 1.63 & 0.05 \\
\hline rho-statistic & 0.17 & 0.57 \\
\hline PP-statistic & -0.37 & 0.35 \\
\hline ADF-statistic & -2.26 & 0.01 \\
\hline \multicolumn{3}{|c|}{ Alternative hypothesis: individual autoregressive coefficients } \\
\hline Group rho-statistic & 1.68 & 0.95 \\
\hline Group PP-statistic & 0.52 & 0.70 \\
\hline Group ADF-statistic & -2.13 & 0.02 \\
\hline
\end{tabular}

Table 1. Tests for Unit Root and Cointegration

Notes: Panel unit root tests are based on Hadri (2000), with the null hypothesis of stationarity. Panel cointegration tests are based on Pedroni $(1999,2004)$, with the null hypothesis of no cointegration. 
Table 2. Estimates of the Cointegration Vector

\begin{tabular}{|c|c|c|c|c|c|c|c|}
\hline & (1) & $(2)$ & (3) & (4) & (5) & (6) & (7) \\
\hline Commodity terms of trade & $\begin{array}{l}0.402 \\
(4.62)\end{array}$ & $\begin{array}{c}0.363 \\
(4.5)\end{array}$ & $\begin{array}{l}0.387 \\
(4.52)\end{array}$ & $\begin{array}{l}0.444 \\
(4.67)\end{array}$ & & & \\
\hline Relative GDP per capita & $\begin{array}{l}0.210 \\
(3.34)\end{array}$ & $\begin{array}{l}0.213 \\
(3.37)\end{array}$ & $\begin{array}{l}0.173 \\
(2.61)\end{array}$ & & $\begin{array}{c}0.198 \\
(2.5)\end{array}$ & & \\
\hline Net foreign assets (in \% of GDP) & $\begin{array}{l}-0.026 \\
(-0.69)\end{array}$ & & & & & $\begin{array}{c}0.021 \\
(0.6)\end{array}$ & \\
\hline Net foreign assets (in \% of trade) & & $\begin{array}{l}-0.033 \\
(-1.26)\end{array}$ & & & & & $\begin{array}{l}-0.004 \\
(-0.15)\end{array}$ \\
\hline
\end{tabular}

Notes: The cointegration vector for the real effective exchange rate and specified variables is estimated by the dynamic OLS methodology with a lead and a lag of one period. T-values are in parenthesis. The panel dataset comprises 21 advanced countries and is on an annual basis for 1981-2008. The list of countries and the data description are detailed in the Appendix. The estimation of coefficients and standard errors is based on Mark and Sul (2003).

relationship between this variable and the REER, ${ }^{2}$ the country's GDP per capita relative to its trading partners to control for the Balassa-Samuelson effect, and net foreign assets to control for the so-called transfer effect. Theory suggests that the coefficients should be positive for each variable. A description of the data is provided in the Appendix. As shown in the upper panel of Table 1, the unit root test of Hadri (2000) rejects the null hypothesis of stationary for all variables.

Following Lane and Milesi-Ferretti (2004), we use dynamic OLS regression with a lead and a lag of one period, to estimate the cointegrating vector. The specification is

$$
\begin{aligned}
W_{i t}= & \alpha_{i}+\beta_{N F A} N F A_{i t}+\beta_{R Y} \log \left(R Y_{i t}\right)+\beta_{T O T} \log \left(T O T_{i t}\right) \\
& +\sum_{j=-1}^{1} \gamma_{N F A, j} \Delta N F A_{i t+j}+\sum_{j=-1}^{1} \gamma_{R Y, j} \Delta \log \left(R Y_{i t+j}\right)+\sum_{j=-1}^{1} \gamma_{T O T, j} \Delta \log \left(T O T_{i t+j}\right)+\varepsilon_{i t}
\end{aligned}
$$

where $N F A_{i t}, R Y_{i t}$, and $T O T_{i t}$ are the ratio of net foreign assets to GDP or to trade, the relative GDP per capita with trading partners, and the commodity-based terms of trade, respectively.

The estimates of the coefficients $\left(\beta_{N F A}, \beta_{R Y}, \beta_{T O T}\right)$ are summarized in Table 2. As shown in the multivariate regressions (columns $1-3$ ), coefficients for the terms of trade and the relative GDP per capita are significant with correct signs, but the coefficient for net foreign assets is not significant, regardless of whether we normalize it by GDP or trade. Bivariate regressions (columns 4-7) provide the same result. Cointegration tests for the REER, the relative GDP

\footnotetext{
${ }^{2}$ Commodity-based terms of trade are the ratio of a weighted average price of the main commodity exports to a weighted average price of the main commodity imports. See Lee et al (2008) for details.
} 
Figure 1. REER and Bilateral Exchange Rate vis-à-vis U.S. Dollar, 1985-2008
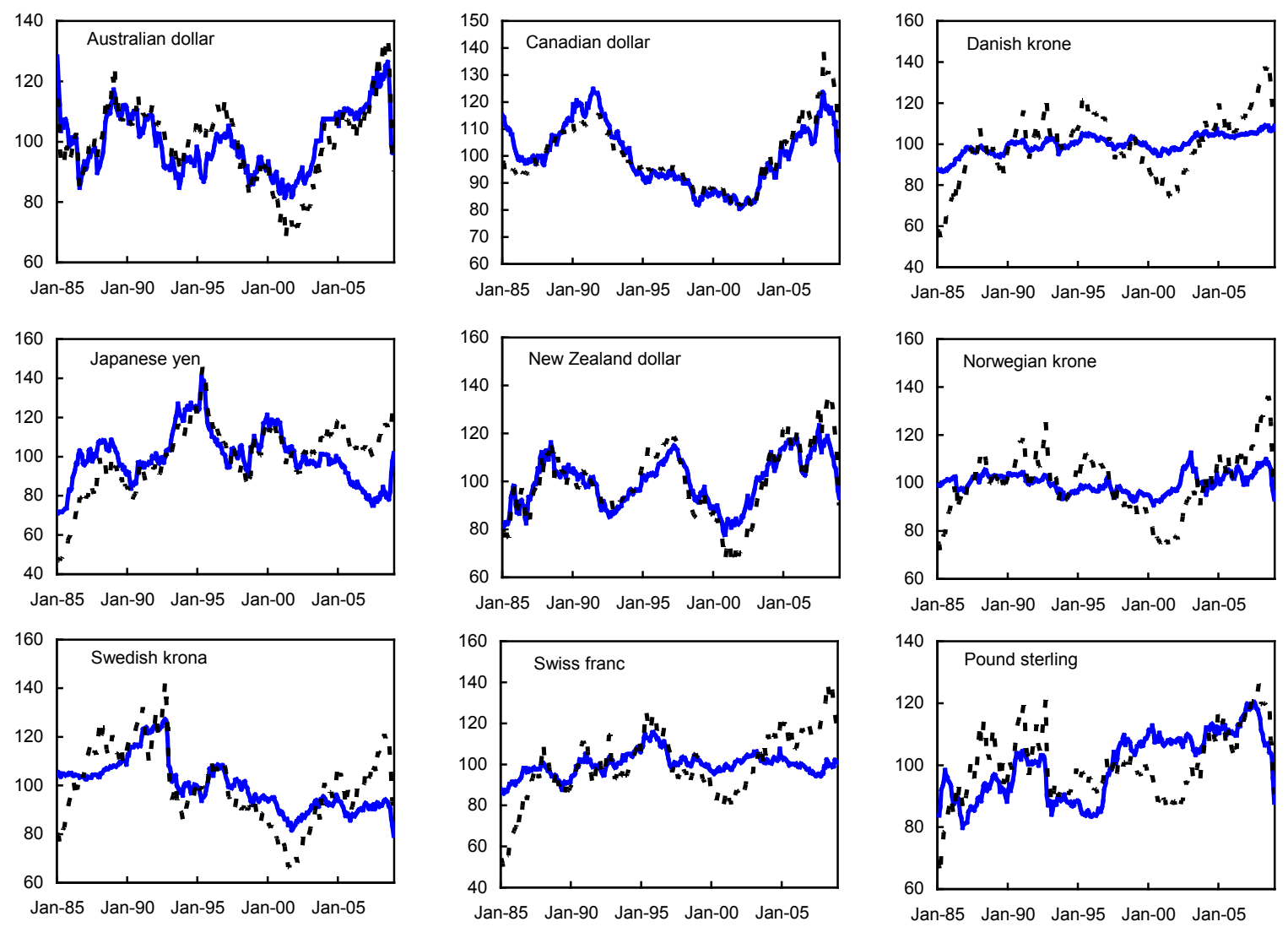

Notes: For each currency, the solid line and the dotted line show the real effective exchange rate (REER) and the bilateral spot exchange rate vis-à-vis U.S. dollar, respectively. An increase means appreciation. All series are normalized with an average for 1985-2008 equal to 100 .

per capita, and the commodity-based terms of trade, reported in the lower panel of Table 1, show that the null hypothesis of no cointegration is rejected in three out of seven tests, but is accepted in the rest. Thus, we proceed as planned, assuming cointegration.

Given these results, we compute the equilibrium real effective exchange rate for country $i$ and year $t$ as follows:

$$
W_{i t}^{*}=\hat{\beta}_{R Y} \log \left(R Y_{i t}\right)+\hat{\beta}_{T O T} \log \left(T O T_{i t}\right)+\hat{\alpha}_{i},
$$

where $\hat{\beta}_{R Y}$ and $\hat{\beta}_{\text {TOT }}$ are the coefficient estimates from column 3 of Table $2\left(\hat{\beta}_{R Y}=0.173\right.$ and $\hat{\beta}_{T O T}=0.387$ ), and $\hat{\alpha}_{i}$ is the estimated country fixed effect from this regression.

$W_{i t}^{*}$ is computed on an annual basis because of data limitation, but the actual real effective exchange rate is available on a monthly basis. Therefore, under the fundamental and hybrid strategies, investors adjust their positions each month. Also, whereas the fundamental value of a foreign currency is measured on a real effective basis, the base currency to calculate returns for currency speculation is the U.S. dollar. However, this does not limit the validity of our analysis, because the REERs are generally driven by bilateral nominal exchange rates vis-à-vis the U.S. dollar (see Figure 1). 


\section{RESUlTS}

\section{A. The Sharpe Ratio ANd SKeWnesS}

In Table 3, we report statistics and measures of investment performance by currency and by strategy. The table lists the mean, the standard deviation, the Sharpe ratio, the skewness, the excess kurtosis, and the result of the Jack-Bera test for normality. These statistics are calculated from monthly observations from February 1985 to December 2008. The Sharpe ratio measures risk-adjusted average returns, derived by dividing the sample mean by the standard deviation. ${ }^{3}$ If returns are negatively skewed, its distribution has a fatter lower tail, and hence returns are subject to "crash risk." A positive value of the excess kurtosis implies that the distribution has a sharper peak and fatter tails than a normal distribution. The JackBera test checks the null hypothesis that the distribution is normal. In addition to nine individual currencies, Table 3 also reports the performance of an "equally weighted" portfolio, which comprises all currencies with a weight of 1/9 for each currency.

We first look at the Sharpe ratio and the skewness of individual currencies. We observe a general tradeoff between the carry trade strategy (a higher Sharpe ratio but negatively skewed returns) and the fundamental strategy (a lower Sharpe ratio but positively skewed returns). The hybrid strategies generally fit into the middle of the tradeoff mentioned above, as expected by definition.

For seven out of nine currencies, the Sharpe ratio is much higher for carry trades than for the fundamental strategy. In particular, the fundamental strategy for the Canadian dollar, the Norwegian krone, and the Swedish krona resulted in a negative average rate of return for the sample period. On the other hand, for eight out of nine currencies, returns are more negatively skewed for carry trades than for the fundamental strategy. In fact, returns to the carry trade strategy are negatively skewed for all currencies, but returns to the fundamental strategy are positively skewed for six out of nine currencies.

For six out of nine currencies, the Sharpe ratio of one of the two hybrid strategies is higher than that of the fundamental strategy and lower than that of the carry trade strategy. For eight currencies, the skewness of returns for one of the two hybrid strategies is lower than that of the fundamental strategy and higher than that of the carry trade strategy. At the same time, we also observe that the hybrid strategy is superior to the carry trade strategy for five currencies, with a higher Sharpe ratio and less negatively skewed returns (the Danish krone, the Japanese yen, the Swiss franc, the Norwegian krone with $\alpha=0.10$, and the pound sterling with $\alpha=0.05$ ). This suggests that the hybrid strategy could offer some insurance against crash risks without sacrificing a high riskadjusted average return achieved by the carry trade strategy.

\footnotetext{
${ }^{3}$ To estimate the standard error of the Sharpe ratio, we assume that the monthly rate of returns is not i.i.d., and follow the methodology of Lo (2002).
} 
Table 3. Performance of Currency Speculation Strategies

\begin{tabular}{|c|c|c|c|c|c|c|c|c|c|}
\hline & Mean & $\begin{array}{l}\text { Standard } \\
\text { deviation }\end{array}$ & $\begin{array}{c}\text { Sharpe } \\
\text { ratio }\end{array}$ & $\begin{array}{l}\text { S.E. of } \\
\text { Sharpe }\end{array}$ & Skewness & $\begin{array}{c}\text { S.E. of } \\
\text { skewness }\end{array}$ & $\begin{array}{l}\text { Excess } \\
\text { kurtosis }\end{array}$ & $\begin{array}{l}\text { S. E. of } \\
\text { kurtosis }\end{array}$ & $\begin{array}{c}\text { P-value of } \\
\text { J-B test }\end{array}$ \\
\hline \multicolumn{10}{|l|}{ Australian dollar } \\
\hline Fundamental & 0.000 & 0.033 & 0.013 & 0.058 & -0.010 & 0.145 & 0.758 & 0.289 & 0.041 \\
\hline Hybrid, $\alpha=0.05$ & 0.001 & 0.033 & 0.038 & 0.056 & -0.041 & 0.145 & 0.766 & 0.289 & 0.037 \\
\hline Hybrid, $\alpha=0.10$ & 0.005 & 0.033 & 0.143 & 0.065 & -0.502 & 0.145 & 1.078 & 0.289 & 0.000 \\
\hline Carry trade & 0.005 & 0.033 & 0.146 & 0.069 & -0.638 & 0.145 & 1.164 & 0.289 & 0.000 \\
\hline \multicolumn{10}{|l|}{ Canadian dollar } \\
\hline Fundamental & 0.000 & 0.019 & -0.013 & 0.056 & -0.524 & 0.145 & 2.674 & 0.289 & 0.000 \\
\hline Hybrid, $\alpha=0.05$ & 0.000 & 0.019 & 0.020 & 0.057 & 0.263 & 0.145 & 2.683 & 0.289 & 0.000 \\
\hline Hybrid, $\alpha=0.10$ & 0.001 & 0.019 & 0.028 & 0.059 & 0.125 & 0.145 & 2.691 & 0.289 & 0.000 \\
\hline Carry trade & 0.001 & 0.019 & 0.054 & 0.068 & -0.271 & 0.145 & 2.776 & 0.289 & 0.000 \\
\hline \multicolumn{10}{|l|}{ Danish krone } \\
\hline Fundamental & 0.001 & 0.032 & 0.019 & 0.066 & 0.217 & 0.145 & -0.136 & 0.289 & 0.285 \\
\hline Hybrid, $\alpha=0.05$ & 0.005 & 0.031 & 0.174 & 0.067 & -0.077 & 0.145 & -0.071 & 0.289 & 0.827 \\
\hline Hybrid, $\alpha=0.10$ & 0.006 & 0.031 & 0.180 & 0.061 & -0.132 & 0.145 & -0.030 & 0.289 & 0.652 \\
\hline Carry trade & 0.005 & 0.032 & 0.153 & 0.063 & -0.143 & 0.145 & -0.037 & 0.289 & 0.604 \\
\hline \multicolumn{10}{|l|}{ Japanese yen } \\
\hline Fundamental & 0.002 & 0.035 & 0.053 & 0.063 & -0.486 & 0.145 & 2.085 & 0.289 & 0.000 \\
\hline Hybrid, $\alpha=0.05$ & 0.002 & 0.035 & 0.064 & 0.063 & -0.511 & 0.145 & 2.118 & 0.289 & 0.000 \\
\hline Hybrid, $\alpha=0.10$ & 0.002 & 0.035 & 0.051 & 0.060 & -0.514 & 0.145 & 2.086 & 0.289 & 0.000 \\
\hline Carry trade & 0.001 & 0.035 & 0.029 & 0.066 & -0.676 & 0.145 & 2.053 & 0.289 & 0.000 \\
\hline \multicolumn{10}{|l|}{ New Zealand dollar } \\
\hline Fundamental & 0.001 & 0.035 & 0.029 & 0.063 & 0.142 & 0.145 & 0.854 & 0.289 & 0.010 \\
\hline Hybrid, $\alpha=0.05$ & 0.003 & 0.035 & 0.089 & 0.064 & -0.012 & 0.145 & 0.887 & 0.289 & 0.012 \\
\hline Hybrid, $\alpha=0.10$ & 0.004 & 0.035 & 0.118 & 0.064 & -0.093 & 0.145 & 0.938 & 0.289 & 0.006 \\
\hline Carry trade & 0.006 & 0.035 & 0.186 & 0.067 & -0.296 & 0.145 & 1.153 & 0.289 & 0.000 \\
\hline \multicolumn{10}{|l|}{ Norwagian krone } \\
\hline Fundamental & -0.003 & 0.032 & -0.103 & 0.062 & 0.172 & 0.145 & 0.582 & 0.289 & 0.077 \\
\hline Hybrid, $\alpha=0.05$ & 0.001 & 0.032 & 0.044 & 0.065 & 0.102 & 0.145 & 0.484 & 0.289 & 0.221 \\
\hline Hybrid, $\alpha=0.10$ & 0.006 & 0.031 & 0.187 & 0.068 & -0.038 & 0.145 & 0.567 & 0.289 & 0.167 \\
\hline Carry trade & 0.005 & 0.031 & 0.152 & 0.070 & -0.204 & 0.145 & 0.649 & 0.289 & 0.036 \\
\hline \multicolumn{10}{|l|}{ Swedish krona } \\
\hline Fundamental & -0.002 & 0.032 & -0.048 & 0.070 & 0.268 & 0.145 & 0.607 & 0.289 & 0.024 \\
\hline Hybrid, $\alpha=0.05$ & 0.001 & 0.032 & 0.037 & 0.071 & 0.121 & 0.145 & 0.536 & 0.289 & 0.148 \\
\hline Hybrid, $\alpha=0.10$ & 0.004 & 0.032 & 0.111 & 0.064 & -0.021 & 0.145 & 0.576 & 0.289 & 0.161 \\
\hline Carry trade & 0.005 & 0.032 & 0.174 & 0.073 & -0.432 & 0.145 & 0.890 & 0.289 & 0.000 \\
\hline \multicolumn{10}{|l|}{ Swiss franc } \\
\hline Fundamental & 0.003 & 0.035 & 0.087 & 0.060 & 0.160 & 0.145 & -0.132 & 0.289 & 0.477 \\
\hline Hybrid, $\alpha=0.05$ & 0.001 & 0.035 & 0.042 & 0.063 & -0.123 & 0.145 & -0.055 & 0.289 & 0.678 \\
\hline Hybrid, $\alpha=0.10$ & 0.002 & 0.035 & 0.045 & 0.058 & -0.181 & 0.145 & -0.043 & 0.289 & 0.449 \\
\hline Carry trade & 0.001 & 0.035 & 0.028 & 0.061 & -0.346 & 0.145 & -0.037 & 0.289 & 0.058 \\
\hline \multicolumn{10}{|l|}{ Pound sterling } \\
\hline Fundamental & 0.000 & 0.031 & 0.013 & 0.067 & 0.074 & 0.145 & 2.387 & 0.289 & 0.000 \\
\hline Hybrid, $\alpha=0.05$ & 0.003 & 0.031 & 0.102 & 0.060 & 0.056 & 0.145 & 2.418 & 0.289 & 0.000 \\
\hline Hybrid, $\alpha=0.10$ & 0.003 & 0.031 & 0.092 & 0.065 & -0.290 & 0.145 & 2.538 & 0.289 & 0.000 \\
\hline Carry trade & 0.003 & 0.031 & 0.093 & 0.065 & -0.302 & 0.145 & 2.544 & 0.289 & 0.000 \\
\hline \multicolumn{10}{|c|}{ Equally weighted portfolio } \\
\hline Fundamental & 0.000 & 0.012 & 0.020 & 0.064 & 0.211 & 0.145 & 1.205 & 0.289 & 0.000 \\
\hline Hybrid, $\alpha=0.05$ & 0.002 & 0.012 & 0.187 & 0.067 & 0.288 & 0.145 & 2.082 & 0.289 & 0.000 \\
\hline Hybrid, $\alpha=0.10$ & 0.003 & 0.014 & 0.240 & 0.076 & 0.061 & 0.145 & 2.454 & 0.289 & 0.000 \\
\hline Carry trade & 0.004 & 0.015 & 0.235 & 0.081 & -0.640 & 0.145 & 1.456 & 0.289 & 0.000 \\
\hline
\end{tabular}

Notes: Statistics are calculated from monthly observations of excess returns for currency speculation strategies, from February 1985 to December 2008. "S.E." stands for standard errors. "J-B test" stands for Jack-Bera test for normality. 
Figure 2. Sharpe Ratio and Skewness for Currency Speculation Strategies

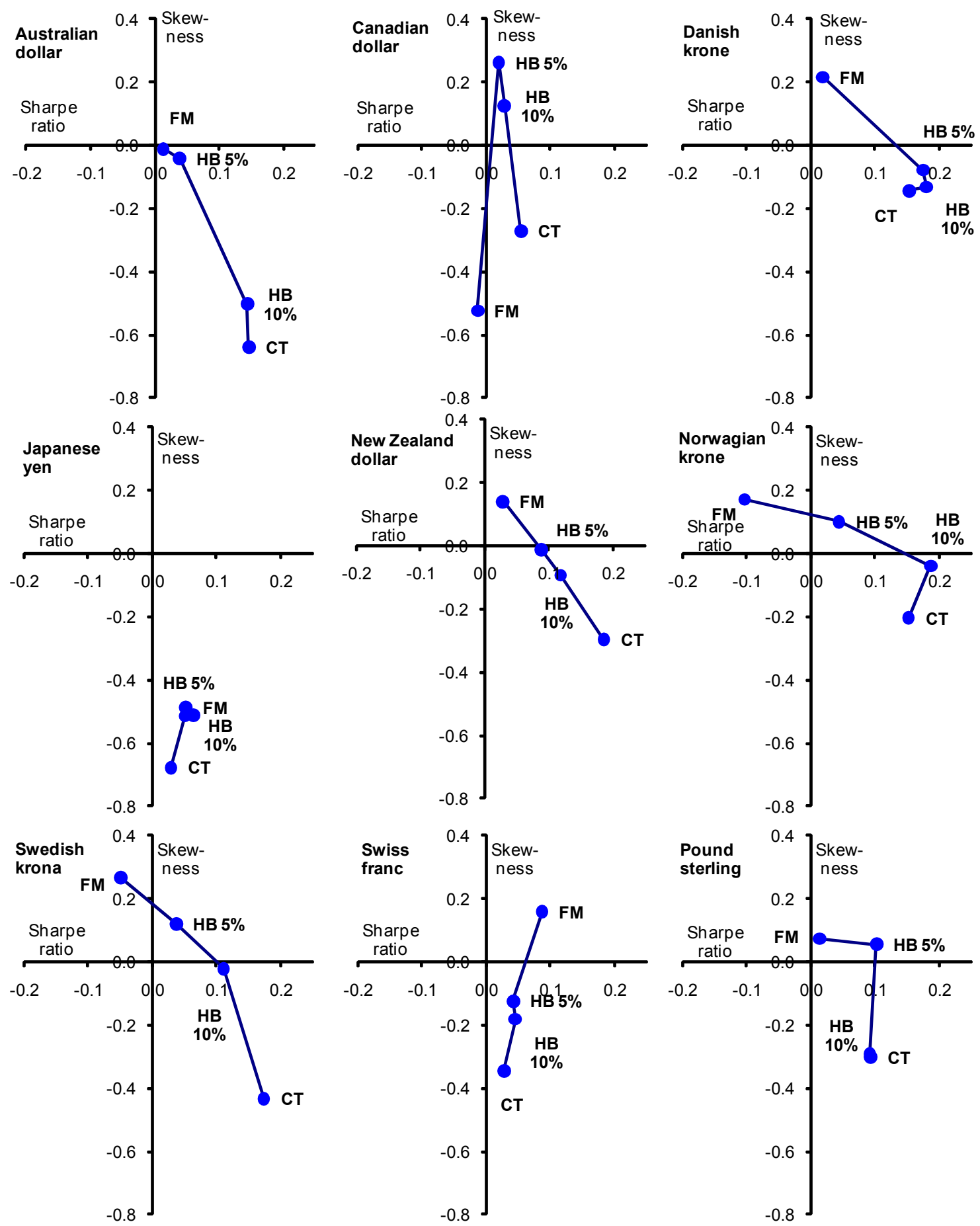

Notes: "FM" and "CT" stand for the fundamental and the carry trade strategies, respectively. "HB $5 \%$ " and "HB 10\%" stand for the hybrid strategies with $\alpha=0.05$ and $\alpha=0.10$, respectively. 
These relationships are more vividly observed in a panel of scatter plots of the Sharpe ratio and skewness by currency (see Figure 2). In general, the line connecting the four strategies has a negative slope, with the carry trade strategy at the lower-right end (a higher Sharpe ratio but negatively skewed returns) and the fundamental strategy at the upper-left end (a lower Sharpe ratio but positively skewed returns). The outliers are the Japanese yen and the Swiss franc, for which the fundamental strategy resulted in a higher Sharpe ratio and a better score for skewness than the carry trade strategy.

For the equally weighted portfolio, the hybrid strategies indeed perform very well (Figure 3). In terms of the Sharpe ratio, the hybrid strategy with $\alpha=0.10$ achieves the highest score (0.240), followed by the carry trade strategy (0.235), the hybrid strategy with $\alpha=0.05$ (0.187), and the fundamental strategy (0.020). The Sharpe ratio of the carry trade and the hybrid strategies is substantially higher than that of the U.S. stock market: the monthly Sharpe ratio for the S\&P 500 was 0.103 for February 1985-December 2008. The returns are negatively skewed for the carry trade strategy (-0.640), but positively skewed for the rest. Interestingly, returns are more positively skewed for the hybrid strategy with $\alpha=0.05(0.288)$ than for the fundamental strategy (0.211). Thus, for the diversified portfolio, the hybrid strategy overcomes the tradeoff that exists between the fundamental and carry trade strategies for individual currencies.

Finally, the excess kurtosis is large and positive except for the Danish krone and the Swiss franc, suggesting that the distribution has a sharper peak and fatter tails than normal distribution. Within each currency, there is no notable difference regarding the kurtosis by strategy. The results of the Jack-Bera test for normality suggest that the carry trade strategy has a non-normal distribution except for the Danish krone and the Swiss franc, while the fundamental and the hybrid strategies have a non-normal distribution for five out of nine currencies. $^{4}$

\footnotetext{
${ }^{4}$ The maximum likelihood test for autoregressive conditional heteroskedasticity (ARCH) rejects the null hypothesis of no ARCH effects for the Australian dollar, the Canadian dollar, the New Zealand dollar, the Norwegian krone, the Swedish krona, and the pound sterling (regardless of strategies). For the equally weighted portfolio, the test rejected the null hypothesis of no ARCH effects for the carry trade strategy and the hybrid strategy with $\alpha=0.10$, but the null is accepted for the fundamental strategy and the hybrid strategy with $\alpha=0.05$.
} 
Table 4. Performance of Currency Speculation Strategies: Subsamples

\begin{tabular}{|c|c|c|c|c|c|c|c|c|c|}
\hline & Mean & $\begin{array}{l}\text { Standard } \\
\text { deviation }\end{array}$ & $\begin{array}{c}\text { Sharpe } \\
\text { ratio }\end{array}$ & $\begin{array}{l}\text { S.E. of } \\
\text { Sharpe }\end{array}$ & Skewness & $\begin{array}{c}\text { S.E. of } \\
\text { skewness }\end{array}$ & $\begin{array}{l}\text { Excess } \\
\text { kurtosis }\end{array}$ & $\begin{array}{l}\text { S. E. of } \\
\text { kurtosis }\end{array}$ & $\begin{array}{c}\text { P-value of } \\
\text { J-B test }\end{array}$ \\
\hline \multicolumn{10}{|l|}{ Full sample } \\
\hline Fundamental & 0.000 & 0.012 & 0.020 & 0.064 & 0.211 & 0.145 & 1.205 & 0.289 & 0.000 \\
\hline Hybrid, $\alpha=0.05$ & 0.002 & 0.012 & 0.187 & 0.067 & 0.288 & 0.145 & 2.082 & 0.289 & 0.000 \\
\hline Hybrid, $\alpha=0.10$ & 0.003 & 0.014 & 0.240 & 0.076 & 0.061 & 0.145 & 2.454 & 0.289 & 0.000 \\
\hline Carry trade & 0.004 & 0.015 & 0.235 & 0.081 & -0.640 & 0.145 & 1.456 & 0.289 & 0.000 \\
\hline \multicolumn{10}{|c|}{ Subsample: February 1985-December 1996} \\
\hline Fundamental & 0.001 & 0.012 & 0.115 & 0.097 & 0.566 & 0.205 & 2.084 & 0.410 & 0.000 \\
\hline Hybrid, $\alpha=0.05$ & 0.004 & 0.011 & 0.317 & 0.093 & 0.855 & 0.205 & 4.239 & 0.410 & 0.000 \\
\hline Hybrid, $\alpha=0.10$ & 0.005 & 0.014 & 0.347 & 0.093 & 0.552 & 0.205 & 3.545 & 0.410 & 0.000 \\
\hline Carry trade & 0.004 & 0.016 & 0.288 & 0.115 & -0.812 & 0.205 & 1.865 & 0.410 & 0.000 \\
\hline \multicolumn{10}{|c|}{ Subsample: January 1997-December 2008} \\
\hline Fundamental & -0.001 & 0.012 & -0.076 & 0.077 & -0.166 & 0.204 & 0.017 & 0.408 & 0.723 \\
\hline Hybrid, $\alpha=0.05$ & 0.001 & 0.012 & 0.071 & 0.085 & -0.075 & 0.204 & 0.305 & 0.408 & 0.764 \\
\hline Hybrid, $\alpha=0.10$ & 0.002 & 0.014 & 0.139 & 0.108 & -0.378 & 0.204 & 1.201 & 0.408 & 0.004 \\
\hline Carry trade & 0.003 & 0.015 & 0.181 & 0.116 & -0.468 & 0.204 & 1.076 & 0.408 & 0.003 \\
\hline
\end{tabular}

Notes: Statistics are calculated from monthly observations of excess returns of the equally weighted portfolio. "S.E." stands for standard errors. "J-B test" stands for Jack-Bera test for normality.

Are these results dependent on the sample period? To see this, we split the sample period in half at December 1996 and report the performance of the equally weighted portfolio for each subsample in Table 4 . We observe that returns to the carry trade strategy have a higher Sharpe ratio and are more negatively skewed in the first subsample. Also, the performance of the fundamental and the hybrid strategies is much better in the first subsample, with a higher Shape ratio and positively skewed returns. Nevertheless, the tradeoff observed in the full sample between the carry trade, the hybrid, and the fundamental strategies is generally preserved in both subsamples.

\section{B. The SOURCE OF NEgative SKEWNESS AND IMPROVEMENTS UNDER THE FUNDAMENTAL STRATEGY}

What contributes to the negative skewness of the carry trade strategy, and why are the fundamental strategy and the hybrid strategies better in this regard? To consider this question, we define a "dismal" month for carry trades as a month in which the return under the carry trade strategy is lower than its sample mean minus two standard deviations. We then count the number of dismal months for carry trades for each currency and the equally weighted portfolio, and recalculate the skewness of returns excluding observations for the dismal months. The result is reported in Table 5A. The number of dismal months for carry trades ranges from 7 (the Japanese yen and the pound sterling) to 13 (the Canadian dollar) out of the total of 287 months. As shown in the table, if we exclude observations for these months, the skewness improves and is no longer negative in all cases except for the Swiss franc. Thus, we conclude that the negative skewness of the carry trade strategy is attributed to the performance in dismal months.

We then identify the dismal months for carry trades, and compare returns realized in these months under all four strategies. As shown in Table 5A, the fundamental strategy performs 
Table 5A. Sources of Negative Skewness for the Carry Trade Strategy

\begin{tabular}{|c|c|c|c|c|c|}
\hline & $\begin{array}{c}\text { Australian } \\
\text { dollar }\end{array}$ & $\begin{array}{c}\text { Canadian } \\
\text { dollar }\end{array}$ & $\begin{array}{l}\text { Danish } \\
\text { krone }\end{array}$ & $\begin{array}{c}\text { Japanese } \\
\text { yen }\end{array}$ & $\begin{array}{c}\text { New } \\
\text { Zealand } \\
\text { dollar }\end{array}$ \\
\hline Skewness for CT & -0.64 & -0.27 & -0.14 & -0.68 & -0.30 \\
\hline Skewness for CT, excluding dismal months of CT & 0.02 & 0.69 & 0.15 & 0.01 & 0.29 \\
\hline Number of dismal months of CT & 10 & 13 & 10 & 7 & 9 \\
\hline Of which: FM results in a higher return than $\mathrm{CT}$ & 5 & 3 & 6 & 1 & 5 \\
\hline Of which: HB w/ $\alpha=0.05$ results in a higher return than $\mathrm{CT}$ & 3 & 3 & 4 & 1 & 3 \\
\hline Of which: $\mathrm{HB} w / \alpha=0.10$ results in a higher return than $\mathrm{CT}$ & 1 & 2 & 1 & 1 & 2 \\
\hline \multirow[t]{2}{*}{ Total number of months } & 287 & 287 & 287 & 287 & 287 \\
\hline & $\begin{array}{l}\text { Norwegian } \\
\text { krone }\end{array}$ & $\begin{array}{l}\text { Swedish } \\
\text { krona }\end{array}$ & Swiss franc & $\begin{array}{l}\text { Pound } \\
\text { sterling }\end{array}$ & $\begin{array}{c}\text { Equally } \\
\text { weighted } \\
\text { portfolio }\end{array}$ \\
\hline Skewness for CT & -0.20 & -0.43 & -0.35 & -0.30 & -0.64 \\
\hline Skewness for CT, excluding dismal months of CT & 0.21 & 0.06 & -0.05 & 0.49 & 0.12 \\
\hline Number of dismal months of CT & 8 & 9 & 8 & 7 & 12 \\
\hline Of which: FM results in a higher return than $\mathrm{CT}$ & 3 & 6 & 6 & 3 & 10 \\
\hline Of which: HB w/ $\alpha=0.05$ results in a higher return than $\mathrm{CT}$ & 3 & 5 & 4 & 2 & 10 \\
\hline Of which: $\mathrm{HB} w / \alpha=0.10$ results in a higher return than $\mathrm{CT}$ & 3 & 3 & 2 & 0 & 5 \\
\hline Total number of months & 287 & 287 & 287 & 287 & 287 \\
\hline
\end{tabular}

Table 5B. Realized Returns of the Equally Weighted Portofolio during Dismal Months of CT (In percent)

\begin{tabular}{lcccc}
\hline & & & $\mathrm{HB}$ & $\mathrm{HB}$ \\
Dismal months of CT & $\mathrm{CT}$ & $\mathrm{FM}$ & $\mathrm{w} / \mathrm{\alpha}=0.05$ & $\mathrm{w} / \mathrm{\alpha}=0.10$ \\
\hline & & & & \\
March 1985 & -3.52 & -0.57 & -0.57 & -3.89 \\
April 1991 & -4.34 & 3.79 & -1.00 & -1.19 \\
July 1991 & -2.79 & 1.77 & -0.62 & -1.78 \\
November 1992 & -5.90 & 1.98 & -1.24 & -2.51 \\
July 1993 & -2.84 & 2.43 & -1.37 & -2.84 \\
April 1995 & -2.95 & -3.72 & -3.72 & -2.95 \\
November 1998 & -3.43 & -0.15 & -1.24 & -2.22 \\
May 2006 & -2.80 & -1.81 & -1.20 & -0.37 \\
September 2008 & -4.52 & 2.87 & 2.15 & -4.52 \\
October 2008 & -3.49 & 0.72 & -1.47 & -3.49 \\
November 2008 & -4.25 & -1.84 & -1.96 & -4.25 \\
December 2008 & -3.98 & -4.14 & -4.14 & -3.98 \\
& & & & \\
\hline
\end{tabular}

Notes: A dismal month of carry trades (CT) is defined as a month in which the excess return for the carry trade strategy is lower than its sample mean minus two sample standard deviations for February 1985-December 2008. "FM" and "HB" stand for the fundamental and the hybrid strategies, respectively.

well in the dismal months for carry trades. In five out of nine currencies (the Australian dollar, the Danish krone, the New Zealand dollar, the Swedish krona, and the Swiss franc), the fundamental strategy achieved higher returns than the carry trade strategy in more than half of the dismal months for carry trades. Note that in those months, the fundamental strategy resulted in a return higher than the carry trade strategy's mean plus two standard deviations. The improvement under the hybrid strategy is also substantial, but less so than under the fundamental strategy. 
In the case of the equally weighted portfolio, the advantage of taking into account the fundamental value of currencies is much more evident. The fundamental strategy and the hybrid strategy with $\alpha=0.05$ outperform the carry trade strategy in 10 months out of 12 dismal months for carry trades. As shown in Table 5B, the outperformance over the carry trade strategy is substantial, especially for the fundamental strategy.

Thus, taking currency fundamentals into account provide investors with considerable insurance against crash risks. The results also suggest that the extremely low returns of the carry trade strategy in dismal months - the source of negative skewness of returns - originate from the adjustment of exchange rates towards their fundamental values. Some researchers argue that such an adjustment is nonlinear in the sense that the larger the overvaluation or the undervaluation against its fundamental value, the faster the exchange rate adjustment (Taylor et al (2001)). The better performance of the hybrid strategies is also consistent with this proposition, because large undervaluation or overvaluation of the exchange rate may adjust so fast that it matters even for investors who change their positions on a monthly basis.

\section{The Optimal InVESTMENT RATio}

In this subsection, we present a simple exercise to examine which strategy a utilitymaximizing investor would choose. We consider an investor with a constant relative risk aversion (CRRA) utility function and a non-financial income $Y_{t}$, who chooses an amount of investment $Q_{t}$ for currency speculation. For simplicity, we assume that the investor cannot save a part of the non-financial income for consumption in the subsequent period. We also assume that the investor faces no minimum margin requirement so that she can choose any amount for $Q_{t}$. Under these assumptions and with real excess returns of currency investment denoted by $\tilde{Z}_{t}$, the investor's consumption $C_{t}$ equals $Y_{t}+Q_{t} \tilde{Z}_{t}$. With a discount factor $\beta<1$, the optimization problem is to maximize

$$
E_{0} \sum_{t=0}^{\infty} \beta^{t} u\left(C_{t}\right)=E_{0} \sum_{t=0}^{\infty} \beta^{t}\left(\frac{\left(Y_{t}+Q_{t} \tilde{Z}_{t}\right)^{1-\sigma}}{1-\sigma}\right)
$$

with respect of $Q_{t}$. It is further assumed that $Y_{t}$ grows at a constant rate $g$ and the investor chooses a time-invariant ratio of the investment amount to income, i.e., $q=Q_{t} / Y_{t}$ for all $t$. With parameter values that satisfy $\beta(1+g)^{1-\sigma}<1$, the maximand becomes

$$
E_{0} \sum_{t=0}^{\infty} \beta^{t} u\left(C_{t}\right)=E_{0}\left(\frac{\left(1+q \tilde{Z}_{t}\right)^{1-\sigma}}{1-\sigma}\right) \cdot \sum_{t=o}^{\infty} \beta^{t} Y_{t}^{1-\sigma}=A \cdot E_{0}\left(\frac{\left(1+q \tilde{Z}_{t}\right)^{1-\sigma}}{1-\sigma}\right)
$$

where $A=Y_{0}^{1-\sigma} /\left(1-\beta(1+g)^{1-\sigma}\right)$. The utility level depends on the component $V=E_{0}\left(\frac{\left(1+q \tilde{Z}_{t}\right)^{1-\sigma}}{1-\sigma}\right)$.

We focus on realized returns under the equally weighted portfolio of each strategy, and solve the problem numerically based on a kernel density estimation of $\tilde{Z}_{t}$, derived by monthly 
Table 6. Optimal Investment and Utility Levels

\begin{tabular}{lcc}
\hline & $q$ & $V$ \\
\hline$\sigma=2$ & & \\
$\quad$ Carry trade & 6.11 & $-1,938$ \\
Fundamental & 0.74 & $-2,064$ \\
Hybrid with $\alpha=0.05$ & 7.07 & $-2,104$ \\
Hybrid with $\alpha=0.10$ & 7.20 & $-1,780$ \\
$\sigma=3$ & & \\
Carry trade & 4.16 & -965 \\
Fundamental & 0.49 & $-1,032$ \\
Hybrid with $\alpha=0.05$ & 4.75 & $-1,049$ \\
Hybrid with $\alpha=0.10$ & 4.88 & -886 \\
$\sigma=5$ & & \\
Carry trade & 2.54 & -481 \\
Fundamental & 0.30 & -516 \\
Hybrid with $\alpha=0.05$ & 2.86 & -523 \\
Hybrid with $\alpha=0.10$ & 2.96 & -441 \\
\hline
\end{tabular}

realized returns. The optimal ratio and the corresponding utility level $V$ is reported in Table 6 by strategy and for three values of the CRRA parameter $(\sigma=2,3$, and 5).

The result of this exercise shows that investors would have a strong preference for the hybrid strategy. Regardless of CRRA parameter values, the optimal investment-to-income ratio and the corresponding utility level is higher for the hybrid strategy with $\alpha=0.10$ than for the carry trade strategy. The result is consistent with our observation that the hybrid strategy seems to overcome the tradeoff between the carry trade and the fundamental strategies.

Note that the utility function we use here does not take into account preference for skewed returns. When such preference is incorporated, as suggested by Brunnermeier, Gollier, and Parker (2007), an investor's preference for the hybrid strategy could be more palpable.

\section{CurRency Speculation AND the Global Financial Crisis}

How did the currency speculation strategies perform during the recent episode of the global financial crisis? To see this, we calculate an ex post nominal asset value index for each strategy with a starting value of 100 in July 2007. Because currency speculation returns $Z_{i t}$ are excess returns over the risk free rate $R_{t}$, the index is defined as $A_{i T}=100 \times \prod_{t=1}^{T}\left(1+R_{t}+Z_{i t}\right)$, with $t=0$ corresponding to July 2007 .

Table 7 shows the index value as of end-2008, by currency and strategy. Most indices for the carry trade strategy fell substantially below par, except for the Danish krone and the Swiss franc, to values of around 80. In stark contrast, the fundamental strategy outperformed the carry trade strategy for all currencies, and the asset value remained above par for 5 currencies and the equally weighted portfolio. Similarly, the hybrid strategies performed better than the carry trade strategy for six currencies, but generally fell short of the fundamental strategy. This suggests that the recent global crisis coincided with exchange rate corrections toward 
Table 7. Performance of Currency Speculation Strategies during the Recent Global Crisis (Cumulative position as of December 2008, with July $2007=100$ )

\begin{tabular}{lcccc}
\hline & Carry trade & Fundamental & Hybrid $5 \%$ & Hybrid $10 \%$ \\
\hline Australian dollar & & & & \\
Canadian dollar & 82.9 & 90.8 & 79.3 & 81.3 \\
Danish krone & 83.9 & 92.5 & 104.5 & 94.2 \\
Japanese yen & 100.6 & 110.6 & 110.6 & 100.6 \\
New Zealand dollar & 83.7 & 104.4 & 100.9 & 88.5 \\
Norwegian krone & 76.9 & 112.8 & 92.6 & 78.4 \\
Swedish krona & 78.4 & 89.9 & 89.9 & 89.9 \\
Swiss franc & 78.1 & 88.7 & 88.7 & 74.1 \\
Pound sterling & 106.3 & 115.0 & 106.3 & 106.3 \\
Equally weighted portfolio & 80.5 & 122.4 & 122.4 & 81.6 \\
& 86.1 & 103.5 & 99.9 & 88.7 \\
\hline
\end{tabular}

estimated fundamental values - the contingency insured by the fundamental strategy and (to a lesser extent) the hybrid strategies.

To explain the better performance of the fundamental strategy during the crisis, we look at the pre-crisis background. We first define an index of divergence between the fundamental and the carry trade strategies as follows:

$$
D V_{t}=\frac{1}{9} \sum_{i=1}^{9} I_{i t}, \text { where for currency } i, I_{i t}=\left\{\begin{array}{cc}
1 & \text { if } X_{i t}^{C T} \neq X_{i t}^{F M} \\
0 & \text { otherwise. }
\end{array}\right.
$$

If $I_{i t}$ equals one, the two strategies are in disagreement, and the carry trade strategy tells investors to go short on an undervalued currency or go long on an overvalued currency. We also define an index of the gap between the actual real effective exchange rate and its estimated fundamental value, by summing up the absolute value of the estimated overvaluation or undervaluation for all currencies. In other words, the exchange rate gap index is defined as

$$
G A P_{t}=\sum_{i=1}^{9}\left|W_{i t}^{*}-W_{i t}\right|
$$

Figure 4 reports these indices together with the CBOE Volatility Index (VIX), a well-known measure of the global risk appetite. The index of divergence rose from mid-2001 to mid2007, implying that carry traders aggravated exchange rate misalignments during this period by selling undervalued currencies and buying overvalued currencies. Consistent with this, the exchange rate gap index rose from mid-2003 to mid-2007, and then declined over the next 12 months, while the VIX index moved in the opposite direction during this period. These observations suggest a possibility that rising risk appetite as seen in the decline in the VIX index could have lessened the carry traders' concern about crash risk. As we saw in Table 7, the crash risk materialized after mid-2007, in tandem with a rise in the VIX index, and a tightening of borrowing conditions in the global market. The sharp rise in the exchange rate gap index since July 2008 reflected the fact that the exchange rate adjustment overshot the estimated degree of overvaluation or undervaluation for the Australian dollar, the Canadian dollar, the Japanese yen and the pound sterling. 


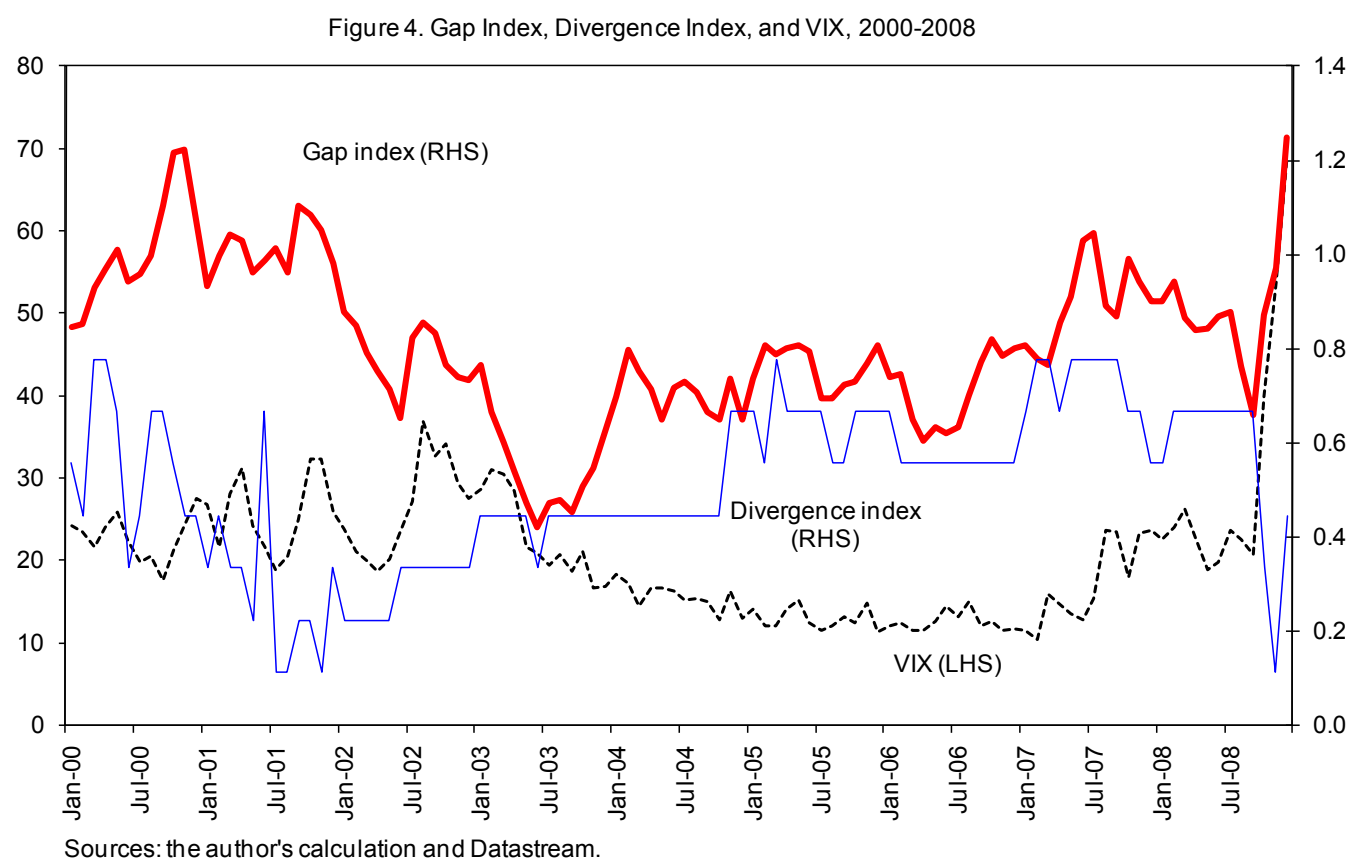

Overall, these developments can be characterized as a boom-bust cycle in the currency market. Under this hypothesis, carry trades created a "bubble" in the sense that they aggravated overvaluation or undervaluation vis-à-vis the fundamental value of the currencies. The bubble eventually burst at the onset of the global crisis. This could explain Brunnermeier et al (2008)'s observation that rising risk aversion as measured by the VIX index coincides with increased losses for carry traders. Of course, this hypothesis is built on assumptions that capital flows created by carry trades were large enough to influence the exchange rate, and carry traders were not worried about crash risks during the boom period. In any case, the divergence and exchange rate gap indices constructed above could help policymakers spot vulnerabilities in the currency market, and serve as an early warning signal.

\section{ROBUSTNESS ISSUES AND EXTENSIONS}

\section{A. No Hindsight CASE}

In this subsection, we produce alternative estimates of the fundamental values of currencies and compare them with our base case results. In the previous section, investors are assumed to have perfect hindsight, because the estimates of the fundamental values of currencies at any point in time (e.g., for 1990) are based on the regression coefficient estimated for the full sample through 2008. This assumption may be too strong especially if the coefficient estimate is sensitive to the choice of the sample period.

To check the sensitivity of coefficient estimates to the sample period, we construct a set of subsample periods by fixing the starting year at 1981 and changing the end year from 1994 to 2008, and run dynamic OLS regressions. Figure 5 illustrates the coefficient estimate for the relative GDP per capita and commodity-based terms of trade, together with a 95 percent 
Figure 5. Panel Regression Coefficients with Moving Sample Periods
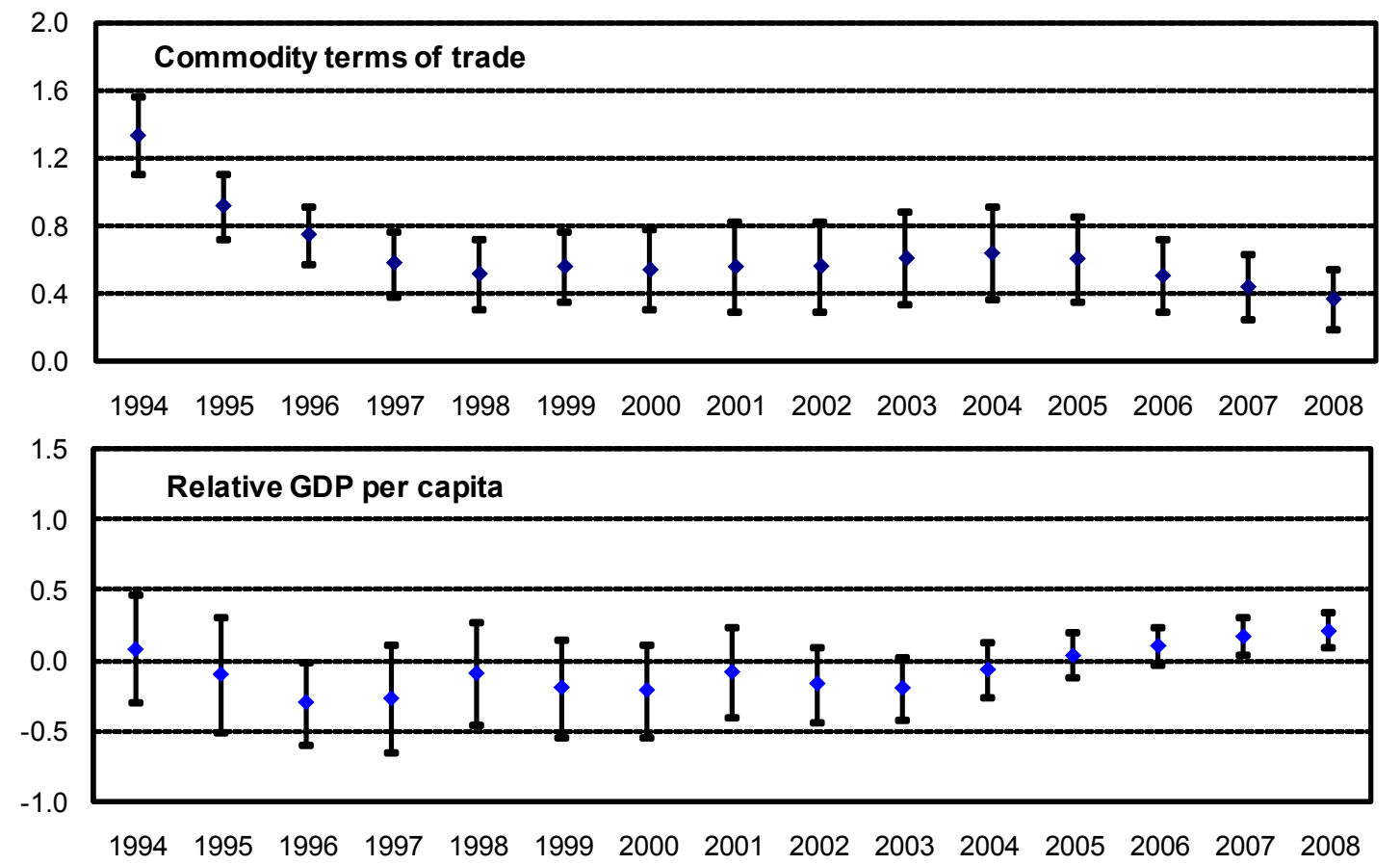

Notes: These charts show the coefficient estimates and 95 percent confidence intervals from dynamic OLS panel regressions of the real effective exchange rate on commodity terms of trade and relative GDP per capita, with moving sample periods. Namely, for each year, the coefficient estimate and the 95 percent confidence interval for each variable is derived by the regression with the sample period from 1981 to that year.

confidence interval. The lower panel shows that the coefficient estimate on the relative GDP per capita is in fact very sensitive to the sample period, and becomes significantly positive only after 2007. In contrast, the coefficient on terms of trade variable is significantly positive for all subsamples.

Based on this result, we introduce the fundamental value of currencies on a no hindsight basis for the fundamental and hybrid strategies, denoted by $W_{t}^{T O T^{*}}$, defined as

$$
W_{i t}^{T O T *}=\widehat{\beta}_{T O T, t} T O T_{i t}+\widehat{\alpha}_{i t}, t=1, \ldots, T,
$$

where $\left(\widehat{\alpha}_{i, t}, \widehat{\beta}_{T O T, t}\right)$ are the coefficient estimates of the dynamic OLS for a sample period ending at $t$.

Figure 6 illustrates the performance of currency speculation strategies under the no hindsight case, with scatter plots of the Sharpe ratio and the skewness for each currency. The solid line represents the no hindsight case, and the dotted line represents the base case under perfect hindsight. The negative slope of the scatter plot is generally observed in the no hindsight case, suggesting the existence of the tradeoff between the carry trade strategy (a higher Sharpe ratio but negatively skewed returns) and the fundamental strategy (a lower Sharpe ratio but positively skewed returns), as seen in the base case. 
Figure 6. Sharpe Ratio and Skewness for Currency Speculation Strategies (No Hindsight Case)
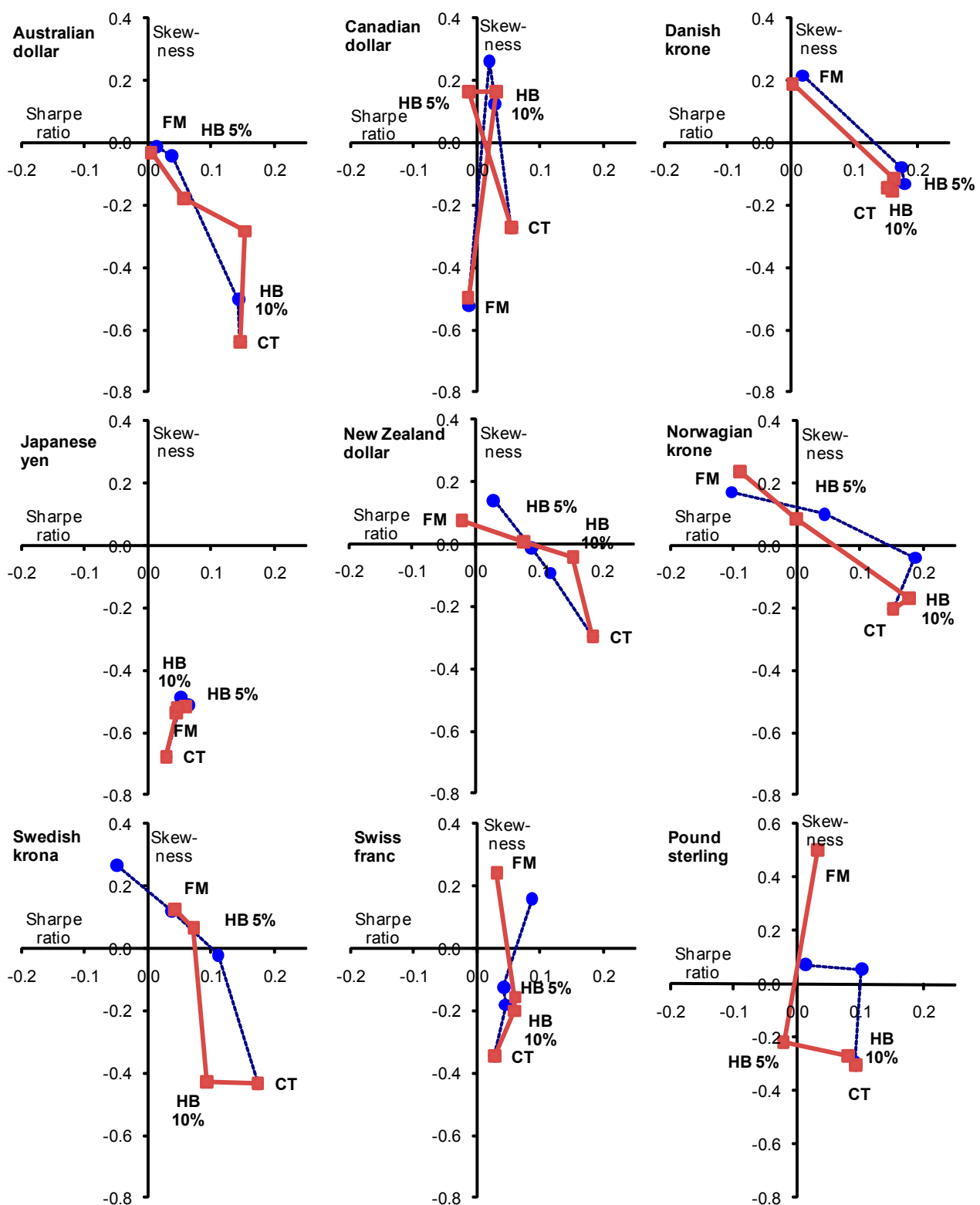

Notes: Solid lines and dotted lines are for the no hindsight case and the base case, respectively.

Table 8A summarizes the performance of the equally weighted portfolio for the no hindsight case. It shows that the hybrid strategies under the no hindsight assumption still perform well compared with the carry trade strategy, with positively skewed returns. In contrast to the base case, however, returns to the fundamental strategy are negatively skewed under the no hindsight assumption. Table $8 \mathrm{~B}$ presents the analysis on the dismal months of carry trades, and shows that the results of the base case still hold under the no hindsight case. Table $8 \mathrm{C}$ reports the optimal investment ratios for the diversified portfolio under the no hindsight alternative, as we did in Section III. C. The utility level is higher for the hybrid strategies than for the carry trade strategy. This result is in line with that of the base case. 
Table 8A. Performance of Currency Speculation Strategies: No Hindsight Case

\begin{tabular}{lccccccccc}
\hline & Mean & $\begin{array}{c}\text { Standard } \\
\text { deviation }\end{array}$ & $\begin{array}{c}\text { Sharpe } \\
\text { ratio }\end{array}$ & $\begin{array}{c}\text { S.E. of } \\
\text { Sharpe }\end{array}$ & $\begin{array}{c}\text { Skewness } \\
\text { skewness }\end{array}$ & $\begin{array}{c}\text { S.E. of } \\
\text { skurtosis }\end{array}$ & $\begin{array}{c}\text { S. E. of } \\
\text { kurtosis }\end{array}$ & $\begin{array}{c}\text { P-value of } \\
\text { J-B test }\end{array}$ \\
\hline Base case & & & & & & & & & \\
$\quad$ Fundamental & 0.000 & 0.012 & 0.020 & 0.064 & 0.211 & 0.145 & 1.205 & 0.289 & 0.000 \\
$\quad$ Hybrid, $\alpha=0.05$ & 0.002 & 0.012 & 0.187 & 0.067 & 0.288 & 0.145 & 2.082 & 0.289 & 0.000 \\
$\quad$ Hybrid, $\alpha=0.10$ & 0.003 & 0.014 & 0.240 & 0.076 & 0.061 & 0.145 & 2.454 & 0.289 & 0.000 \\
$\quad$ Carry trade & 0.004 & 0.015 & 0.235 & 0.081 & -0.640 & 0.145 & 1.456 & 0.289 & 0.000 \\
No hindsight case & & & & & & & & & \\
$\quad$ Fundamental & 0.000 & 0.012 & 0.013 & 0.068 & -0.229 & 0.145 & 2.335 & 0.289 & 0.000 \\
$\quad$ Hybrid, $\alpha=0.05$ & 0.002 & 0.012 & 0.148 & 0.080 & 0.143 & 0.145 & 5.648 & 0.289 & 0.000 \\
$\quad$ Hybrid, $\alpha=0.10$ & 0.003 & 0.015 & 0.227 & 0.078 & 0.126 & 0.145 & 2.485 & 0.289 & 0.000 \\
$\quad$ Carry trade & 0.004 & 0.015 & 0.235 & 0.081 & -0.640 & 0.145 & 1.456 & 0.289 & 0.000 \\
\hline
\end{tabular}

Notes: Statistics are calculated from monthly observations of excess returns of the equally weighted portfolio. "S.E." stands for standard errors. "J-B test" stands for Jack-Bera test for normality.

Table 8B. Sources of Negative Skewness for the Carry Trade Strategy (No Hindsight Case)

\begin{tabular}{|c|c|c|c|c|c|c|c|c|c|c|}
\hline & \multicolumn{2}{|c|}{ Australian dollar } & \multicolumn{2}{|c|}{ Canadian dollar } & \multicolumn{2}{|c|}{ Danish krone } & \multicolumn{2}{|c|}{ Japanese yen } & \multicolumn{2}{|c|}{$\begin{array}{c}\text { New Zealand } \\
\text { dollar }\end{array}$} \\
\hline & $\begin{array}{l}\text { Base } \\
\text { case }\end{array}$ & $\begin{array}{c}\text { No HS } \\
1 /\end{array}$ & $\begin{array}{l}\text { Base } \\
\text { case }\end{array}$ & $\begin{array}{c}\text { No HS } \\
1 /\end{array}$ & $\begin{array}{l}\text { Base } \\
\text { case }\end{array}$ & $\begin{array}{c}\text { No HS } \\
1 /\end{array}$ & $\begin{array}{l}\text { Base } \\
\text { case }\end{array}$ & $\begin{array}{c}\text { No HS } \\
1 /\end{array}$ & $\begin{array}{l}\text { Base } \\
\text { case }\end{array}$ & $\begin{array}{c}\text { No HS } \\
1 /\end{array}$ \\
\hline Skewness for CT & -0.64 & $\ldots$ & -0.27 & $\ldots$ & -0.14 & $\ldots$ & -0.68 & $\ldots$ & -0.30 & $\ldots$ \\
\hline Skewness for CT, excluding dismal months of $\mathrm{CT}$ & 0.02 & $\ldots$ & 0.69 & $\ldots$ & 0.15 & $\ldots$ & 0.01 & $\ldots$ & 0.29 & $\ldots$ \\
\hline Number of dismal months of CT & 10 & $\ldots$ & 13 & $\ldots$ & 10 & $\ldots$ & 7 & $\ldots$ & 9 & $\ldots$ \\
\hline Of which: FM results in a higher return than CT & 5 & 4 & 3 & 3 & 6 & 6 & 1 & 1 & 5 & 4 \\
\hline Of which: $\mathrm{HB}$ w/ $\alpha=0.05$ results in a higher return than CT & 3 & 2 & 3 & 2 & 4 & 3 & 1 & 1 & 3 & 4 \\
\hline Of which: $\mathrm{HB} w / \alpha=0.10$ results in a higher return than $\mathrm{CT}$ & 1 & 2 & 2 & 1 & 1 & 0 & 1 & 1 & 2 & 2 \\
\hline \multirow[t]{3}{*}{ Total number of months } & 287 & 287 & 287 & 287 & 287 & 287 & 287 & 287 & 287 & 287 \\
\hline & \multicolumn{2}{|c|}{ Norwegian krone } & \multicolumn{2}{|c|}{ Swedish krona } & \multicolumn{2}{|c|}{ Swiss franc } & \multicolumn{2}{|c|}{ Pound sterling } & \multicolumn{2}{|c|}{$\begin{array}{c}\text { Eq. weighted } \\
\text { portfolio }\end{array}$} \\
\hline & $\begin{array}{l}\text { Base } \\
\text { case }\end{array}$ & $\begin{array}{c}\text { No HS } \\
1 /\end{array}$ & $\begin{array}{l}\text { Base } \\
\text { case }\end{array}$ & $\begin{array}{c}\text { No HS } \\
1 /\end{array}$ & $\begin{array}{l}\text { Base } \\
\text { case }\end{array}$ & $\begin{array}{c}\text { No HS } \\
1 /\end{array}$ & $\begin{array}{l}\text { Base } \\
\text { case }\end{array}$ & $\begin{array}{c}\text { No HS } \\
1 /\end{array}$ & $\begin{array}{l}\text { Base } \\
\text { case }\end{array}$ & $\begin{array}{c}\text { No HS } \\
1 /\end{array}$ \\
\hline Skewness for CT & -0.20 & $\ldots$ & -0.43 & $\ldots$ & -0.35 & $\ldots$ & -0.30 & $\ldots$ & -0.64 & $\ldots$ \\
\hline Skewness for $\mathrm{CT}$, excluding dismal months of CT & 0.21 & $\ldots$ & 0.06 & $\ldots$ & -0.05 & $\ldots$ & 0.49 & $\ldots$ & 0.12 & ... \\
\hline Number of dismal months of CT & 8 & $\ldots$ & 9 & $\ldots$ & 8 & $\ldots$ & 7 & $\ldots$ & 12 & $\ldots$ \\
\hline Of which: FM results in a higher return than CT & 3 & 4 & 6 & 5 & 6 & 7 & 3 & 4 & 10 & 9 \\
\hline Of which: $\mathrm{HB} w / \alpha=0.05$ results in a higher return than $\mathrm{CT}$ & 3 & 3 & 5 & 5 & 4 & 4 & 2 & 1 & 10 & 8 \\
\hline Of which: HB w/ $\alpha=0.10$ results in a higher return than CT & 3 & 1 & 3 & 2 & 2 & 3 & 0 & 0 & 5 & 6 \\
\hline Total number of months & 287 & 287 & 287 & 287 & 287 & 287 & 287 & 287 & 287 & 287 \\
\hline
\end{tabular}

Notes: A dismal month of carry trade (CT) is defined as a month in which the excess return for the carry trade strategy is lower than its sample mean minus two sample standard deviations for February 1985-December 2008. "FM" and "HB" stand for the fundamental and the hybrid strategies, respectively.

1/ Results under no hindsight case.

Table 8C. Optimal Investment and Utility Levels

\begin{tabular}{lccccc}
\hline & \multicolumn{2}{c}{ Base case } & & \multicolumn{2}{c}{ No hindsight case } \\
\cline { 2 - 3 } \cline { 5 - 6 } & $q$ & $V$ & & $q$ & $V$ \\
\hline$\sigma=2$ & 6.11 & $-1,938$ & & 6.11 & $-1,938$ \\
$\quad$ Carry trade & 0.74 & $-2,064$ & & 0.48 & $-2,018$ \\
$\quad$ Fundamental & 7.07 & $-2,104$ & & 5.29 & $-1,728$ \\
$\quad$ Hybrid with $\alpha=0.05$ & 7.20 & $-1,780$ & & 6.65 & $-1,765$ \\
$\quad$ Hybrid with $\alpha=0.10$ & & & & & \\
$\sigma=3$ & 4.16 & -965 & & 4.16 & -965 \\
$\quad$ Carry trade & 0.49 & $-1,032$ & & 0.32 & $-1,009$ \\
Fundamental & 4.75 & $-1,049$ & & 3.57 & -862 \\
Hybrid with $\alpha=0.05$ & 4.88 & -886 & & 4.49 & -879 \\
Hybrid with $\alpha=0.10$ & & & & & \\
$\sigma=5$ & 2.54 & -481 & & 2.54 & -481 \\
$\quad$ Carry trade & 0.30 & -516 & & 0.19 & -504 \\
Fundamental & 2.86 & -523 & & 2.16 & -431 \\
Hybrid with $\alpha=0.05$ & 2.96 & -441 & & 2.72 & -438 \\
$\quad$ Hybrid with $\alpha=0.10$ & & & &
\end{tabular}


In summary, these results suggest that our assumption of perfect hindsight under the base case does not seem overly restrictive.

\section{B. GAINS FROM INCORPORATING DETERMINANTS OF CURRENCY FUNDAMENTALS}

In this subsection, we present two alternative measures for the equilibrium REER: a simple historical average and a trend component of the REER. The comparison of these cases with the base case would clarify whether taking into account determinants of the equilibrium REER, most importantly the developments of commodity-based terms of trade, makes a difference. This exercise clarifies how our analysis differs from that of Jordà and Taylor (2009), in which the equilibrium exchange rate is based on the relative PPP and does not depend on its determinants.

The first alternative measure of the equilibrium REER, denoted by $W_{t}^{P P P^{*}}$, is a simple historical mean of the real effective exchange rate:

$$
W_{i t}^{P P P^{*}}=(1 / t) \sum_{s=1}^{t} R E E R_{i s}, t=1, \ldots, T .
$$

This means that an investor choosing the fundamental strategy at time $t$ opts for a short (long) position of a currency if the current observation of the real effective exchange rate is above (below) its historical mean through time $t$. This alternative is associated with the idea of the weak purchasing power parity (PPP).

The second alternative measure is based on the Hodrick-Prescott filter, denoted by $W_{t}^{H P F^{*}}$, and defined as

$$
W_{i t}^{H P F^{*}}=h p\left(R E E R_{i, 1}, \ldots, R E E R_{i, t}\right), t=1, \ldots, T,
$$

where $h p(\cdot)$ transforms the data into HP-filtered series and then returns the last observation. Under this, an investor choosing the fundamental strategy opts for a short (long) position of a currency if the current observation of the real effective exchange rate is above (below) its HP-filtered series.

The performance of these alternatives is summarized in Table 9, together with those of the base case and the no hindsight case. Returns to the fundamental and the hybrid strategies under the PPP case and the HP filter case are calculated based on the corresponding estimates of the equilibrium REER. The statistics are computed for the equally weighted portfolio of the nine currencies.

In general, the two alternative cases do not perform as well as the base case or the no hindsight case. The Shape ratio of the fundamental and the hybrid strategies is generally lower for the PPP and the HP filter cases than for the base case and the no hindsight case. Returns under the fundamental and the hybrid strategies are still negatively skewed for the two alternative cases, with an exception of the fundamental strategy under the PPP case. These results suggest the importance of taking into account terms of trade developments to compute fundamental values. 
Table 9. Performance of Currency Speculation Strategies: PPP and HP Filter Cases

\begin{tabular}{|c|c|c|c|c|c|c|c|c|c|}
\hline & Mean & $\begin{array}{l}\text { Standard } \\
\text { deviation }\end{array}$ & $\begin{array}{c}\text { Sharpe } \\
\text { ratio }\end{array}$ & $\begin{array}{l}\text { S.E. of } \\
\text { Sharpe }\end{array}$ & Skewness & $\begin{array}{c}\text { S.E. of } \\
\text { skewness }\end{array}$ & $\begin{array}{l}\text { Excess } \\
\text { kurtosis }\end{array}$ & $\begin{array}{l}\text { S. E. of } \\
\text { kurtosis }\end{array}$ & $\begin{array}{c}P \text {-value of } \\
\mathrm{J} \text {-B test }\end{array}$ \\
\hline \multicolumn{10}{|l|}{ Base case } \\
\hline Fundamental & 0.000 & 0.012 & 0.020 & 0.064 & 0.211 & 0.145 & 1.205 & 0.289 & 0.000 \\
\hline Hybrid, $\alpha=0.05$ & 0.002 & 0.012 & 0.187 & 0.067 & 0.288 & 0.145 & 2.082 & 0.289 & 0.000 \\
\hline Hybrid, $\alpha=0.10$ & 0.003 & 0.014 & 0.240 & 0.076 & 0.061 & 0.145 & 2.454 & 0.289 & 0.000 \\
\hline Carry trade & 0.004 & 0.015 & 0.235 & 0.081 & -0.640 & 0.145 & 1.456 & 0.289 & 0.000 \\
\hline \multicolumn{10}{|l|}{ No hindsight case } \\
\hline Fundamental & 0.000 & 0.012 & 0.013 & 0.068 & -0.229 & 0.145 & 2.335 & 0.289 & 0.000 \\
\hline Hybrid, $\alpha=0.05$ & 0.002 & 0.012 & 0.148 & 0.080 & 0.143 & 0.145 & 5.648 & 0.289 & 0.000 \\
\hline Hybrid, $\alpha=0.10$ & 0.003 & 0.015 & 0.227 & 0.078 & 0.126 & 0.145 & 2.485 & 0.289 & 0.000 \\
\hline Carry trade & 0.004 & 0.015 & 0.235 & 0.081 & -0.640 & 0.145 & 1.456 & 0.289 & 0.000 \\
\hline \multicolumn{10}{|l|}{ PPP case } \\
\hline Fundamental & -0.001 & 0.014 & -0.051 & 0.061 & 0.100 & 0.145 & 0.983 & 0.289 & 0.003 \\
\hline Hybrid, $\alpha=0.05$ & 0.000 & 0.012 & 0.016 & 0.060 & -0.593 & 0.145 & 1.144 & 0.289 & 0.000 \\
\hline Hybrid, $\alpha=0.10$ & 0.002 & 0.013 & 0.163 & 0.073 & -0.407 & 0.145 & 0.919 & 0.289 & 0.000 \\
\hline Carry trade & 0.004 & 0.015 & 0.235 & 0.081 & -0.640 & 0.145 & 1.456 & 0.289 & 0.000 \\
\hline \multicolumn{10}{|l|}{ HP filter case } \\
\hline Fundamental & -0.005 & 0.014 & -0.386 & 0.049 & -0.862 & 0.145 & 3.675 & 0.289 & 0.000 \\
\hline Hybrid, $\alpha=0.05$ & -0.001 & 0.014 & -0.046 & 0.067 & -0.568 & 0.145 & 2.824 & 0.289 & 0.000 \\
\hline Hybrid, $\alpha=0.10$ & 0.002 & 0.015 & 0.139 & 0.077 & -0.780 & 0.145 & 2.364 & 0.289 & 0.000 \\
\hline Carry trade & 0.004 & 0.015 & 0.235 & 0.081 & -0.640 & 0.145 & 1.456 & 0.289 & 0.000 \\
\hline
\end{tabular}

Notes: Statistics are calculated from monthly observations of excess returns of the equally weighted portfolio. "S.E." stands for standard errors. "J-B test" stands for Jack-Bera test for normality.

\section{Transaction Costs}

Currency speculators have to pay transaction costs, originating from the spread between ask and bid exchange rates. Table 10 tabulates bid-ask spreads for the currencies of interest. As demonstrated by Burnside et al (2006), we observe that transaction costs (i) are higher for forward exchange rates than for spot exchange rates, (ii) are heterogeneous across currencies, and (iii) have declined over time, reflecting technological advance in currency trading. As such, transaction costs may alter the payoff profile of currency speculation.

To see if our base case results are still valid, we calculate currency speculation returns under transaction costs as follows. We denote the ask exchange rate by superscript $A$, and the bid exchange rate by superscript $B$. Then the carry trade strategy under transaction costs is defined as

$$
X_{i t}^{C T}=\left\{\begin{array}{cc}
+1 & \text { if } F_{i t}^{B} / S_{i t}^{A}>1 \\
-1 & \text { if } F_{i t}^{A} / S_{i t}^{B}<1 \\
0 & \text { otherwise. }
\end{array} .\right.
$$


Table 10. Bid-ask Spreads

\begin{tabular}{ccccccccc}
\hline \multicolumn{2}{c}{$\begin{array}{c}\text { Australian } \\
\text { dollar }\end{array}$} & $\begin{array}{c}\text { Canadian } \\
\text { dollar }\end{array}$ & $\begin{array}{c}\text { Danish } \\
\text { krone }\end{array}$ & $\begin{array}{c}\text { Japanese } \\
\text { yen }\end{array}$ & $\begin{array}{c}\text { New Zealand Norwegian } \\
\text { dollar }\end{array}$ & $\begin{array}{c}\text { Swedish } \\
\text { krone }\end{array}$ & $\begin{array}{c}\text { Swiss } \\
\text { krona }\end{array}$ & $\begin{array}{c}\text { Pound } \\
\text { franc }\end{array}$ \\
sterling
\end{tabular}

Notes: Bid-ask spreads in basis points are computed by $\left(\ln \left(\right.\right.$ ask price) $-\ln (\text { bid price) })^{\star} 10000$.

For other strategies, definitions of $X_{i t}$ are the same as in the base case. For all strategies, monthly excess returns under transaction costs are defined as

$$
Z_{i t}= \begin{cases}\left(1+R_{t}\right) X_{i t}\left(\frac{F_{i t}^{B}}{S_{i, t+1}^{A}}-1\right) & \text { for } X_{i t}=+1 \\ \left(1+R_{t}\right) X_{i t}\left(\frac{F_{i, t}^{A}}{S_{i, t+1}^{B}}-1\right) & \text { for } X_{i t}=-1 .\end{cases}
$$

Figure 7 reports the performance of currency speculation strategies under transaction costs, along with that of the base case. A general observation is that the introduction of transaction costs drives down the Sharpe ratio. However, the tradeoff among strategies regarding the Sharpe ratio and the skewness is preserved under transaction costs, except for the Canadian dollar, the Japanese yen, and the Swiss franc, as the connecting line of the scatter plot has a negative slope. Therefore, we conclude that the introduction of transaction costs does not alter our main result. 
Figure 7. Sharpe Ratio and Skewness for Currency Speculation Strategies (with Transaction Costs)
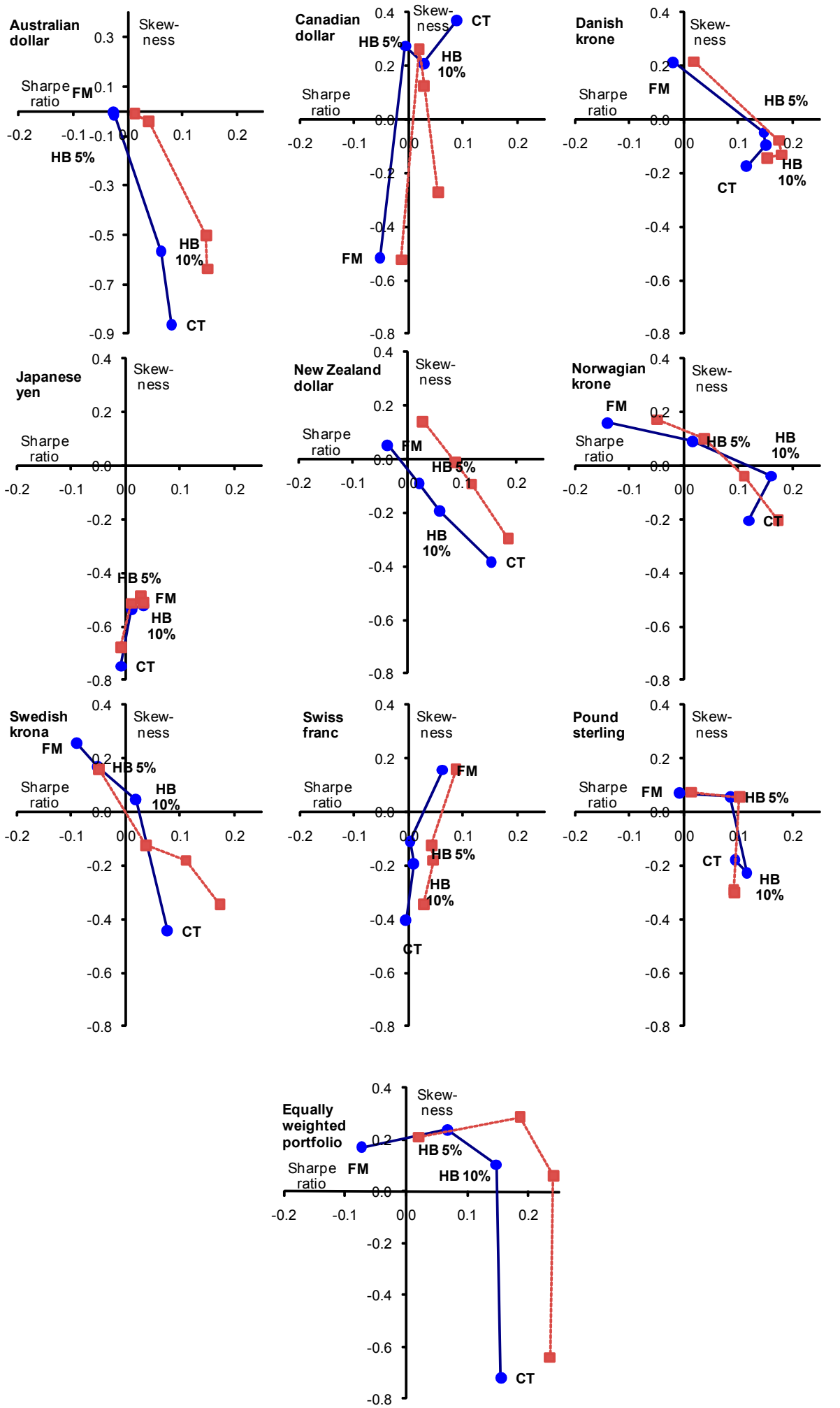

Notes: Solid lines are for the case with transaction costs, and dotted lines are for the base case (without transaction costs). 
Table 11. Correlation with Risk Factors

\begin{tabular}{|c|c|c|c|c|c|c|}
\hline & \multicolumn{3}{|c|}{ Carry Trade } & \multicolumn{3}{|c|}{ Fundamental } \\
\hline & Constant & Coefficie & R-squared & Constant & Coefficie & squared \\
\hline & 0.01 & 0.04 & 0.00 & 0.00 & 0.03 & 0.01 \\
\hline S\&P 500 return & [3.09] & [0.97] & & {$[0.12]$} & [1.15] & \\
\hline \multirow[t]{2}{*}{ MKT } & 0.01 & 0.03 & 0.01 & 0.00 & 0.03 & 0.01 \\
\hline & [3.21] & [0.84] & & [0.19] & [1.19] & \\
\hline \multirow[t]{2}{*}{ HML } & 0.01 & -0.07 & 0.02 & 0.00 & 0.06 & 0.03 \\
\hline & [3.33] & {$[-1.47]$} & & {$[0.50]$} & [1.62] & \\
\hline \multirow[t]{2}{*}{ SMB } & 0.01 & 0.03 & 0.00 & 0.00 & 0.03 & 0.01 \\
\hline & [3.21] & [0.68] & & [0.25] & {$[0.74]$} & \\
\hline \multirow[t]{4}{*}{ Consumption } & 0.01 & 1.45 & 0.03 & 0.00 & 0.73 & 0.01 \\
\hline & [1.17] & [1.72] & & {$[-0.57]$} & [1.18] & \\
\hline & & yybrid, $\alpha=$ & & & brid, $\alpha=$ & \\
\hline & Constant & Coefficie & R-squared & Constant & Coefficie & squared \\
\hline \multirow[t]{2}{*}{ S\&P 500 return } & 0.01 & 0.04 & 0.02 & 0.01 & 0.05 & 0.03 \\
\hline & [2.64] & [1.47] & & [3.37] & [1.57] & \\
\hline \multirow[t]{2}{*}{ MKT } & 0.01 & 0.03 & 0.02 & 0.01 & 0.05 & 0.03 \\
\hline & {$[2.77]$} & [1.38] & & [3.50] & [1.57] & \\
\hline \multirow[t]{2}{*}{ HML } & 0.01 & 0.01 & 0.00 & 0.01 & -0.05 & 0.01 \\
\hline & [3.02] & [0.17] & & [3.73] & {$[-1.04]$} & \\
\hline \multirow[t]{2}{*}{ SMB } & 0.01 & 0.02 & 0.00 & 0.01 & 0.03 & 0.01 \\
\hline & [2.87] & [0.54] & & [3.57] & [0.81] & \\
\hline \multirow[t]{2}{*}{ Consumption } & 0.00 & 0.77 & 0.02 & 0.01 & 1.42 & 0.04 \\
\hline & [1.15] & [1.35] & & [1.27] & [1.96] & \\
\hline
\end{tabular}

Notes: Results of univariate regressions, with quarterly real returns of the equally weighted portfolio as the dependent variable. The sample period is $1985: 1 Q-2008: 4 Q$. "S\&P500" is the real rate of returns for the S\&P 500 portfolio. The three Fama-French factors, "MKT", "HML", and "SMB" are the excess return on a broad market portfolio, the difference between the return on a portfolio of small stocks and the return on a portfolio of large stocks, and the difference between the return on a portfolio of high-book-to-market stocks and the return on a portfolio of low-book-to-market stocks, respectively (see Fama and French (1993) for details). "Consumption" is quarterly percentage change of real per capita consumption in the United States.

\section{Correlation with Risk Factors}

In this subsection, we investigate whether the Sharpe ratio of the currency speculation strategies can be explained by correlations with risk factors. For example, the average return may be lower for the fundamental strategy than for the carry trade strategy because the latter is more positively correlated with consumption. We use a simple method adopted by Burnside et al (2006): for each currency strategy, quarterly real returns of the equally weighted portfolio are regressed onto a risk factor. Our risk factors are per capita consumption growth in the U.S., the returns to the S\&P 500, and the Fama-French (1993) stock market factors. ${ }^{5}$

As reported in Table 11, we find that the real rate of return is not significantly correlated with risk factors for any strategy, with only one exception. Thus, like Burnside et al (2006), we conclude that the correlation between payoffs and risk factors cannot explain the difference in the average return among currency speculation strategies.

${ }^{5}$ The quarterly real return $r_{s}^{q}$ is calculated as $r_{s}^{q}=\frac{1}{1+\pi_{s}}\left(\prod_{j=0}^{2}\left(1+Z_{t-1-j}+R_{t-j}\right)-\prod_{j=0}^{2}\left(1+Z_{t-1-j}\right)\right)$, where $t$ is the index for months, $s$ is the index for quarters, and $\pi_{s}$ is the quarterly inflation rate. 
Table 12. Performance of Currency Speculation Strategies: Commodity Currencies

\begin{tabular}{lccccccccc}
\hline & Mean & $\begin{array}{c}\text { Standard } \\
\text { deviation }\end{array}$ & $\begin{array}{c}\text { Sharpe } \\
\text { ratio }\end{array}$ & $\begin{array}{c}\text { S.E. of } \\
\text { Sharpe }\end{array}$ & Skewness & $\begin{array}{c}\text { S.E. of } \\
\text { skewness }\end{array}$ & $\begin{array}{c}\text { Kurtosis } \\
\text { S. E. of }\end{array}$ & $\begin{array}{c}\text { P-value of } \\
\text { kurtosis }\end{array}$ & J-B test \\
\hline $\begin{array}{l}\text { Commodity currencies } \\
\text { Fundamental }\end{array}$ & -0.001 & 0.017 & -0.030 & 0.057 & -0.082 & 0.145 & 0.948 & 0.289 & 0.005 \\
Hybrid, $\alpha=0.05$ & 0.002 & 0.018 & 0.086 & 0.069 & -0.058 & 0.145 & 0.911 & 0.289 & 0.009 \\
Hybrid, $\alpha=0.10$ & 0.004 & 0.019 & 0.202 & 0.074 & -0.233 & 0.145 & 1.631 & 0.289 & 0.000 \\
$\quad$ Carry trade & 0.004 & 0.020 & 0.218 & 0.078 & -0.369 & 0.145 & 1.457 & 0.289 & 0.000 \\
\hline Non-commodity currencies & & & & & & & & \\
Fundamental & 0.001 & 0.016 & 0.055 & 0.062 & 0.329 & 0.145 & 1.043 & 0.289 & 0.000 \\
Hybrid, $\alpha=0.05$ & 0.003 & 0.016 & 0.175 & 0.061 & 0.258 & 0.145 & 1.253 & 0.289 & 0.000 \\
Hybrid, $\alpha=0.10$ & 0.003 & 0.017 & 0.178 & 0.064 & 0.176 & 0.145 & 1.963 & 0.289 & 0.000 \\
Carry trade & 0.003 & 0.019 & 0.162 & 0.069 & -0.374 & 0.145 & 2.266 & 0.289 & 0.000 \\
\hline
\end{tabular}

Notes: The "commodity-currency" portfolio comprises Australian dollar, Canadian dollar, New Zealand dollar, and Norwegian krone, with equal weights. The "non-commodity" portfolio comprises the rest of the currencies, with equal weights. The returns of the portfolios are calculated from monthly observations of excess returns for the base case, from February 1985 to December 2008.

\section{E. Commodity Currencies}

The currencies of commodity-exporting countries are often called "commodity currencies," and the REER of such countries are found to move in tandem with the prices of their commodity exports (Cashin et al (2004)). According to the criteria of Cashin et al (2004), there are four commodity currencies in our dataset: the Australian dollar, the Canadian dollar, the New Zealand dollar, and the Norwegian krone. In this subsection, we analyze whether a portfolio comprising the four commodity currencies performs differently from that of non-commodity currencies. The portfolio is calculated by using an equal weight (i.e., 1/4 for the commodity-currency portfolio and $1 / 5$ for the non-commodity-currency portfolio).

Table 12 compares the performance of the commodity-currency portfolio and the noncommodity-currency portfolio. For both portfolios, we observe the tradeoff between the carry trade and the fundamental strategies, and the carry trade strategy has a high Sharpe ratio and negatively skewed returns. We also observe that the fundamental and the hybrid strategies perform very well for the portfolio with non-commodity currencies. In particular, the hybrid strategies for this portfolio results in a Sharpe ratio higher than the carry trade strategy and positively skewed returns. This suggests that the result for the equally diversified portfolio of all currencies is not entirely driven by the commodity currencies.

\section{CONCLUSION}

In this paper, we analyze the financial performance of different currency speculation strategies, comparing a carry trade strategy with investment strategies that are guided by the fundamental value of currencies. To do so, we estimate a cointegration relationship between the real effective exchange rate and its fundamental determinants, and calculate returns to the strategy in which investors take a long (short) position if the actual exchange rate is undervalued (overvalued) relative to its fundamental value, and the "hybrid" strategy in which investors switch from the carry trade strategy to the fundamental strategy if and only if 
exchange rate overvaluation or undervaluation exceeds a threshold. Nine advanced-country currencies are examined.

Our findings suggest that currency fundamentals matter for currency speculators. First, there is a tradeoff between the carry trade and the fundamental strategies. Consistent with other studies, we find that returns to the carry trade strategy have a high Sharpe ratio, but are negatively skewed, implying that carry trades are subject to crash risks. In contrast, the fundamental strategy results in a low Sharpe ratio, but its returns are positively skewed in general. Second, the fundamental strategy tends to outperform the carry trade strategy in the period in which the crash risk of carry trades materializes, and hence the consideration of currency fundamentals provides insurance against crash risk. Third, the performance of the hybrid strategy appears to overcome the tradeoff between the carry trade and the fundamental strategies, since its returns achieve a relatively high Sharpe ratio and are less negatively skewed than those from carry trades. Indeed, utility-maximizing investors would prefer the hybrid strategy to the carry trade or to the fundamental strategies. Fourth, the fundamental strategy and the hybrid strategy generally outperformed the carry trade strategy during the recent global financial crisis. All in all, these results suggest that the realization of the crash risk of carry trades tends to coincide with an exchange rate correction toward its fundamental value.

These findings are robust to alternative specifications. The base-case results generally hold for subsample periods as well as under the existence of transaction costs. The use of fullsample parameter estimates for the equilibrium REER does not seem overly restrictive. The use of the relative PPP or the HP filter to compute equilibrium REER results in substantial underperformance of the fundamental and the hybrid strategies relative to the base case, suggesting the importance of the determinants of the equilibrium REER. We also examine the commodity-currency portfolio and the non-commodity-currency portfolio, and confirm that our main result is not entirely driven by commodity currencies.

Our result is counterintuitive to the view of slow adjustment of exchange rates toward their fundamental value. With slow adjustment, exchange rate overvaluation or undervaluation should not matter for investors who change their positions frequently on a monthly basis. However, we find that the fundamental value of a currency carries valuable information for currency speculators, because it signals a possibility of a large and quick adjustment of the exchange rate (i.e., crash risk). This is consistent with the idea of nonlinear adjustments in the exchange rate: the larger the divergence from the equilibrium exchange rate is, the faster the exchange rate adjusts.

The finding that the fundamental strategy outperformed the carry trade strategy during the recent global financial crisis points to a boom-bust cycle in the currency market. Under the pre-crisis global market condition, carry trades aggravated exchange rate overvaluation or undervaluation, since undervalued currencies had lower interest rates, and vice versa. An eventual correction in the exchange rate was triggered at the onset of the global financial crisis. This could explain Brunnermeier et al (2008)'s observation that rising risk aversion as measured by the VIX index coincides with increased losses for carry traders. Based on these 
observations, early warning indicators are proposed to spot vulnerabilities in the currency market.

The main caveat of our analysis is that we do not fully explain how the financial market prices the risks inherent in the currency speculation. We find that the correlation with basic risk factors cannot account for differences in average returns to the currency speculation strategies. Thus, these differences would have to be explained by the skewness of returns. To fully analyze this, we need to incorporate preference for skewness in the decision making of investors. 


\section{Appendix}

\section{Panel regressions in Section 2.2}

Countries included in the panel data: Australia, Austria, Belgium, Canada, Denmark, Finland, France, Germany, Greece, Ireland, Italy, Japan, Netherlands, New Zealand, Norway, Portugal, Spain, Sweden, Switzerland, United Kingdom, and United States.

Real effective exchange rate: the source is the IMF Information Notice System database. The relative price is computed from consumer price indices.

Net foreign assets: a country's net international investment position from the updated database of Lane and Milesi-Ferretti (2007).

Relative GDP per capita: The source of GDP per capita is Penn World Table through 2003 or 2004, and the IMF World Economic Outlook database beyond 2003 or 2004. For each country, the weight for trading partners is the same as that of the real effective exchange rate.

Commodity-based terms of trade: The source is the dataset used under the Equilibrium Real Exchange Rate Approach for IMF's CGER methodology on exchange rate assessments. For details, see Lee et al (2008).

\section{Computation of monthly returns of currency speculation strategies in Section 2.3}

To compute monthly returns, we obtain from Datastream each currency's exchange rates on the first business day of each month from January 1985 to December 2008. $S_{t}$ is the midpoint of the bid and asked spot rates, and $F_{t}$ is the midpoint of the bid and asked rates for 1-month forward exchange rates. 


\section{REFERENCES}

Abiad, Abdul, Prakash Kannan, and Jungjin Lee, 2009, "Evaluating Historical CGER Assessments: How Well Have They Predicted Subsequent Exchange Rate Movements?", IMF Working Paper 09/32.

Brunnermeier, Markus, Stefan Nagel, and Lasse Pedersen, 2008, "Carry Trades and Currency Crashes," NBER Working Paper No. 14473 (Cambridge, Massachusetts: National Bureau of Economic Research).

Brunnermeier, Markus, Christian Gollier, and Jonathan Parker, 2007, "Optimal Beliefs, Asset Prices, and the Preference for Skewed Returns," American Economic Review, Vol. 97, No. 2 (May), pp. 159-165.

Burnside, A. Craig, Martin S. Eichenbaum, Isaak Kleshchelski, and Sergio Rebelo, 2006, "The Returns to Currency Speculation," NBER Working Paper No. 12489 (Cambridge, Massachusetts: National Bureau of Economic Research).

Cashin, Paul, Luis F. Cespédes, and Ratna Sahay, 2004, "Commodity Currencies and the Real Exchange Rate,” Journal of Development Economics, Vol. 75, pp. 239-268.

Fama, Eugene and Kenneth French, 1993, "Common Risk Factors in the Returns on Stocks and Bonds," Journal of Financial Economics, Vol. 33, No. 1, pp. 3-56.

Hadri, Khaddour, 2000, "Testing for Stationarity in Heterogeneous Panel Data," Econometrics Journal, Vol. 3, pp. 148-161.

Jordà, Òscar and Alan M. Taylor, 2009, “The Carry Trade and Fundamentals: Nothing to Fear but FEER Itself,” NBER Working Paper No. 15518 (Cambridge, Massachusetts: National Bureau of Economic Research).

Lane, Philip, and Gian Maria Milesi-Ferretti, 2004, "The Transfer Problem Revisited: Net Foreign Assets and Real Exchange Rates," The Review of Economics and Statistics, Vol. 86, No. 4 (November), pp. 841-857.

Lane, Philip, and Gian Maria Milesi-Ferretti, 2007, "The External Wealth of Nations Mark II: Revised and Extended Estimates of Foreign Assets and Liabilities," Journal of International Economics, No. 73 (November), pp. 223-250.

Lee, Jaewoo, Gian Maria Milesi-Ferretti, Jonathan Ostry, Alessandro Prati, and Luca Antonio Ricci, 2008, Exchange Rate Assessments: CGER Methodologies, IMF Occasional Paper 261 (Washington: International Monetary Fund).

Lo, Andrew, 2002, “The Statistics of Sharpe Ratios," Financial Analysts Journal, Vol. 58, No. 4 (July/August), pp. 36-52. 
Mark, Nelson and Donggyu Sul, 2003. "Cointegration Vector Estimation by Panel DOLS and Long-run Money Demand," Oxford Bulletin of Economics and Statistics, Vol. 65, No. 5, pp. 655-680.

Pedroni, Peter, 1999, "Critical Values for Cointegration Tests in Heterogeneous Panels with Multiple Regressors," Oxford Bulletin of Economics and Statistics, Vol. 61, pp. 653-70.

Pedroni, Peter, 2004, "Panel Cointegration; Asymptotic and Finite Sample Properties of Pooled Time Series Tests with an Application to the PPP Hypothesis," Econometric Theory, Vol. 20, pp. 597-625.

Rogoff, Kenneth, 1996, “The Purchasing Power Parity Puzzle,” Journal of Economic Literature, Vol. 34, No. 2 (June), pp. 647-668.

Taylor, Mark, David Peel, and Lucio Sarno, 2001, "Nonlinear Mean-Reversion in Real Exchange Rates: Towards a Solution to the Purchasing Power Parity Puzzles," International Economic Review, Vol. 42, No. 4, pp. 1015-1042. 